\title{
Tidal forcing, energetics, and mixing near the Yermak Plateau
}

\author{
I. Fer ${ }^{1,3}$, M. Müller ${ }^{2}$, and A. K. Peterson ${ }^{1,3}$ \\ ${ }^{1}$ Geophysical Institute, University of Bergen, Bergen, Norway \\ ${ }^{2}$ Norwegian Meteorological Institute, Oslo, Norway \\ ${ }^{3}$ Bjerknes Centre for Climate Research, Bergen, Norway \\ Correspondence to: I. Fer (ilker.fer@uib.no)
}

Received: 24 August 2014 - Published in Ocean Sci. Discuss.: 8 October 2014

Revised: 3 March 2015 - Accepted: 9 March 2015 - Published: 27 March 2015

\begin{abstract}
The Yermak Plateau (YP), located northwest of Svalbard in Fram Strait, is the final passage for the inflow of warm Atlantic Water into the Arctic Ocean. The region is characterized by the largest barotropic tidal velocities in the Arctic Ocean. Internal response to the tidal flow over this topographic feature locally contributes to mixing that removes heat from the Atlantic Water. Here, we investigate the tidal forcing, barotropic-to-baroclinic energy conversion rates, and dissipation rates in the region using observations of oceanic currents, hydrography, and microstructure collected on the southern flanks of the plateau in summer 2007, together with results from a global high-resolution ocean circulation and tide model simulation. The energetics (depthintegrated conversion rates, baroclinic energy fluxes and dissipation rates) show large spatial variability over the plateau and are dominated by the luni-solar diurnal $\left(K_{1}\right)$ and the principal lunar semidiurnal $\left(M_{2}\right)$ constituents. The volumeintegrated conversion rate over the region enclosing the topographic feature is approximately $1 \mathrm{GW}$ and accounts for about $50 \%$ of the $M_{2}$ and approximately all of the $K_{1}$ conversion in a larger domain covering the entire Fram Strait extended to the North Pole. Despite the substantial energy conversion, internal tides are trapped along the topography, implying large local dissipation rates. An approximate local conversion-dissipation balance is found over shallows and also in the deep part of the sloping flanks. The baroclinic energy radiated away from the upper slope is dissipated over the deeper isobaths. From the microstructure observations, we inferred lower and upper bounds on the total dissipation rate of about 0.5 and $1.1 \mathrm{GW}$, respectively, where about 0.4 $0.6 \mathrm{GW}$ can be attributed to the contribution of hot spots of energetic turbulence. The domain-integrated dissipation
\end{abstract}

from the model is close to the upper bound of the observed dissipation, and implies that almost the entire dissipation in the region can be attributed to the dissipation of baroclinic tidal energy.

\section{Introduction}

The Yermak Plateau (YP, Fig. 1), located northwest of Svalbard, is the main topographic obstacle to the warm Atlantic inflow into the Arctic Ocean. In the vicinity of Svalbard, the marginal ice zone (MIZ), the transition region between open water and dense ice cover, is typically located over the plateau, indicating substantial oceanic heat loss to the melting of sea ice in the region. The YP is identified as a region of enhanced tidal variability for both diurnal and semidiurnal tides (Hunkins, 1986; Padman et al., 1992; D'Asaro and Morison, 1992; Plueddemann, 1992). Strong tidal currents over the sloping flanks of the plateau lead to increased internal wave activity and intense diapycnal mixing of water properties (Padman and Dillon, 1991; Wijesekera et al., 1993; Fer et al., 2010). The mixing in this region is of particular interest because it can contribute to the cooling of the West Spitsbergen Current, which carries warm and saline Atlantic Water through Fram Strait. The heat removed from the Atlantic Water layer can influence the inflowing water mass properties to the Arctic Ocean as well as the regional ice cover north of Svalbard.

The breaking of internal waves is a major source of turbulence-driven diapycnal mixing in the ocean. One generation mechanism of internal waves is the baroclinic response to barotropic tidal flow of a stratified water column 
over favourable topography, such as continental slopes, isolated ridges, or areas of enhanced seafloor roughness (Garrett and Kunze, 2007). Near sites of internal tide generation, some of the energy dissipates locally through the breaking of high-mode, small-scale waves (e.g. Klymak et al., 2008), whereas the remainder propagates away as low-mode internal tides. The propagation of linear plane internal tides is possible; however, only equatorward of the critical latitude at which the Coriolis parameter, $f$, equals the tidal wave frequency, $\omega$. The Coriolis parameter changes with the latitude, $\Psi$, through $f=2 \Omega \sin \Psi$, where $\Omega=7.292 \times 10^{-5} \mathrm{~s}^{-1}$ is the Earth's angular rotation. The critical latitudes for the principal lunar semidiurnal tide $M_{2}$ and the diurnal tides $K_{1}$ and $O_{1}$ are near $74^{\circ} 30^{\prime}$ and $30^{\circ}$, respectively. Poleward of the critical latitude the wave equation changes form from hyperbolic to elliptic, and no progressive linear plane wave solution is allowed (Vlasenko et al., 2005). The solution is evanescent, exists locally where the barotropic-to-baroclinic energy conversion occurs, and decays exponentially in the vertical and in the cross-slope direction. Baroclinic disturbances in response to tidal flow over topography above the critical latitude are thus topographically trapped near the generation site (a continental slope, a ridge, or a seamount). The energy propagation of topographically trapped waves is possible along the slope, around the topographic feature with negligible radiation away in the cross-slope direction. This is analogous to the sub-inertial baroclinic trapped waves propagating around isolated seamounts (Brink, 1989). Trapped tides dissipate their energy locally, or elsewhere along the topography, leading to substantial vertical mixing (Padman and Dillon, 1991; Tanaka et al., 2010; Johnston and Rudnick, 2014).

In general, the generation of near-inertial and sub-inertial internal tides has not obtained much attention, although there are strong signs that they have the potential to impact decadal climate variations (Tanaka et al., 2012; Müller, 2013). A recent numerical study in the Barents Sea shows internal $M_{2}$ tides with bottom-enhanced energy density and dissipation rates, trapped in the vicinity of their generation sites (Kagan and Sofina, 2014). The bottom-trapped tides in the Arctic Ocean are of particular importance because most of the Arctic Basin is located north of critical latitude of the most energetic tidal constituent $M_{2}$. Falahat and Nycander (2014) computed an area-integrated energy flux of about $1.1 \mathrm{GW}$ $\left(1 \mathrm{GW} \equiv 10^{9} \mathrm{~W}\right)$ for topography-trapped internal tides (sum of the $K_{1}, O_{1}$, and $M_{2}$ constituents, where about $70 \%$ is $M_{2}$ ). Estimates from global numerical models of the conversion rates of barotropic-to-baroclinic tidal energy in the Arctic region are roughly $5 \mathrm{GW}$ (Simmons et al., 2004; Müller, 2013).

At the latitudes of the YP, except from the principal solar semidiurnal tide $\left(S_{2}\right.$, with critical latitude near $\left.85^{\circ}\right)$, all diurnal frequencies and the principal $M_{2}$ semidiurnal frequency are sub-inertial; locally generated internal tides are trapped. The critical latitude also serves as a turning latitude for low-mode internal tides generated elsewhere below
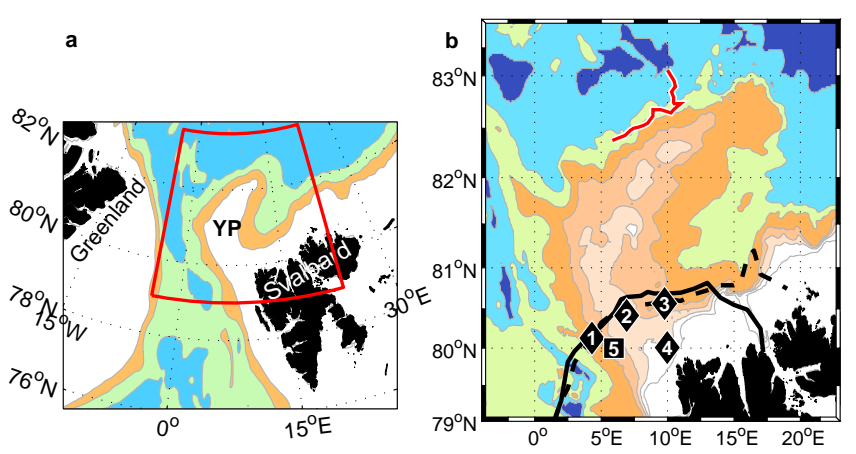

Figure 1. (a) Location map of the study area with the Yermak Plateau (YP) enlarged in (b). Isobaths are drawn at $1000 \mathrm{~m}$ intervals (Global Relief Model, ETOPO5) in (a), and at $250 \mathrm{~m}$ intervals to $1000 \mathrm{~m}$ followed by $1000 \mathrm{~m}$ intervals (ETOPO1; Amante and Eakins, 2009) in (b). Stations 1-5 are marked. Station 5 is co-located with the short-term mooring (rectangle). The drift of the CEAREX-O camp is shown by the red line on the northern flanks. The ice edge digitized from high-resolution ice charts (http://polarview.org/services/hric.htm) provided by the Norwegian Meteorological Institute are shown for 23 (dashed) and 25 July 2007 (solid).

the critical latitude, and propagating poleward. At the YP, $M_{2}$ frequency is only slightly sub-inertial $\left(f \approx 1.025 \omega_{M_{2}}\right.$ ), and an anti-cyclonic relative vorticity can shift the effective Coriolis frequency, $f_{\mathrm{e}}$, relaxing the trapping and the turning latitude. For $f_{\mathrm{e}}<\omega_{M_{2}}$, progressive solutions are allowed: so-called near-inertial vortex-trapped internal waves (Kunze and Toole, 1997). As we show in the following, the YP is a site of substantial barotropic-to-baroclinic energy conversion. It is thus expected that the baroclinic energy extracted from the barotropic tide cannot propagate away and likely dissipates locally, contributing to turbulent mixing where the internal tide is forced. This is supported by observations in the YP region that show localized energetic turbulence and mixing (Padman and Dillon, 1991).

Earlier investigations typically used observations of hydrographic properties and water column velocity sampled from ice camps or by autonomous buoys, see Padman et al. (1992) and Fer et al. (2010) for an overview. Measurements of ocean currents from a drifting buoy showed that energy increased threefold from its level in the Nansen Basin as the buoy passed over the YP (Plueddemann, 1992), dominated by diurnal and near-inertial (semidiurnal) frequencies. Energetic bursts of near-inertial internal wave packets were inferred to propagate upwards, presumably generated by interaction of the barotropic tide with bottom topography. Similarly, D'Asaro and Morison (1992) identified upward propagating near-inertial waves and enhanced eddy diffusivity over the central plateau. Average ocean-to-ice heat fluxes of $22 \mathrm{~W} \mathrm{~m}^{-2}$ were inferred from an automated buoy as it drifted over the northern YP (McPhee et al., 2003). In the pycnocline above the Atlantic Water layer, Padman and Dillon 
Table 1. Summary of station position, sampling duration, and vertical coverage; 5-M is the mooring located near station 5. Water depth is the mean \pm 1 SD over the station duration. The corresponding stretched depth (in stretched metre; sm) and the covered fraction are listed for a range of 3-500 $\mathrm{m}$ for MSS and 12-360 $\mathrm{m}$ for the VM-ADCP.

\begin{tabular}{lrrrrrr}
\hline Station & $\begin{array}{r}\text { Latitude } \\
(\mathrm{N})\end{array}$ & $\begin{array}{r}\text { Longitude } \\
(\mathrm{E})\end{array}$ & $\begin{array}{r}\text { Duration (h) } \\
\text { MSS/ADCP }\end{array}$ & $\begin{array}{r}\text { Water depth } \\
(\mathrm{m})\end{array}$ & $\begin{array}{r}\text { Stretched depth } \\
(\mathrm{sm})\end{array}$ & $\begin{array}{r}\text { Coverage } \\
(\%)\end{array}$ \\
\hline 1 & $80^{\circ} 7.95^{\prime}$ & $4^{\circ} 18.10^{\prime}$ & $24.1 / 24.3$ & $1253 \pm 57$ & 1147 & $64 / 52$ \\
2 & $80^{\circ} 25.14^{\prime}$ & $6^{\circ} 55.24^{\prime}$ & $23.1 / 24.7$ & $637 \pm 9$ & 715 & $84 / 67$ \\
3 & $80^{\circ} 34.00^{\prime}$ & $9^{\circ} 46.73^{\prime}$ & $22.7 / 8.8$ & $1000 \pm 86$ & 828 & $66 / 50$ \\
4 & $80^{\circ} 0.57^{\prime}$ & $9^{\circ} 59.25^{\prime}$ & $24.4 / 18.8$ & $484 \pm 4$ & 567 & $99 / 73$ \\
5 & $80^{\circ} 0.10^{\prime}$ & $5^{\circ} 58.10^{\prime}$ & $24.2 / 4.6$ & $879 \pm 29$ & 988 & $70 / 49$ \\
$5-\mathrm{M}$ & $79^{\circ} 59.78^{\prime}$ & $5^{\circ} 55.95^{\prime}$ & $195.5 / 15.1^{\mathrm{a}}$ & 889 & 990 & $75^{\mathrm{b}}$ \\
\hline
\end{tabular}

a Duration of Microcat sampling/duration of Longranger sampling.

${ }^{b}$ Percentage of the stretched depth covered by the moored Microcats.

(1991) observed an upward heat flux of $25 \mathrm{~W} \mathrm{~m}^{-2}$, which decreased to $6 \mathrm{~W} \mathrm{~m}^{-2}$ below the surface mixed layer. These mixing rates and heat fluxes are strong and comparable to those observed over the shelves north of Svalbard and in proximity to the West Spitsbergen Current branches (Fer and Sundfjord, 2007; Sirevaag and Fer, 2009). Here, we hypothesize that spatially varying tides and their baroclinic response over topography are responsible for the observed variability and mixing near the YP.

In this paper we discuss tidal forcing and the role of tides in mixing near the YP. Our study differs from the earlier work in that we report observations from stations, each occupied typically for 1 day, and an 8-day-long time series from a bottom-anchored mooring. The data set is presented earlier in Fer et al. (2010, hereafter F2010), who reported strong variability in the internal wave activity and vertical mixing at the YP. However, the rate of conversion of surface tide energy to baroclinic energy, the spatial distribution of the baroclinic energy fluxes, and the energy dissipation rates are unknown. The limited observational data set is therefore supplemented with results from a global high-resolution ocean circulation and tide model simulation (STORMTIDE, Müller et al., 2012), to obtain barotropic-to-baroclinic energy conversion rates and baroclinic energy fluxes in the region. A thorough evaluation of model-observation comparison and model performance is not intended in this paper. Our approach is to use the (limited) observations to document the substantial tidal variability and levels of turbulence mixing, and use the tidal model results to infer integrated, regional energetics.

\section{Methods}

\subsection{Observational data}

The site and measurement details are described fully in F2010; only a brief summary is given here. Observations were made in summer 2007 from the R/V Håkon Mosby in southern YP. Sampling was limited by the ice edge in the MIZ, and included five stations and an 8-day-long time series from a mooring (Fig. 1 and Table 1). Each station was occupied for approximately 1 day. Full-depth CTD (conductivity, temperature, depth) profiles were collected using a Sea-Bird Scientific SBE911 plus system. At each station ocean microstructure profiles were taken approximately every 30-60 min (222 casts in total) in the upper $520 \mathrm{~m}$ using a loosely tethered free-fall profiler equipped with shear probes (Micro-Structure Sonde, MSS, manufactured by ISW Wassermesstechnik, Germany). Velocity in the water column was measured by a vessel-mounted Teledyne RD Instruments (RDI) Narrowband $150 \mathrm{kHz}$ acoustic Doppler current profiler (VM-ADCP) in the upper $360 \mathrm{~m}$. Additionally, at station 1 , six velocity profiles at approximately $4 \mathrm{~h}$ interval were collected to the bottom, using eXpendable Current Profilers (XCPs).

The mooring was deployed at a water depth of $889 \mathrm{~m}$, colocated with station 5 . The mooring line was instrumented with 19 SBE37 Microcats recording conductivity, temperature and (16 of them) pressure, distributed between 99 and $873 \mathrm{~m}$; a Teledyne RDI $75 \mathrm{kHz}$ Longranger ADCP at approximately $2 \mathrm{~m}$ above the bottom looking upward and sampling in $8 \mathrm{~m}$ bins; and an Aanderaa (Xylem Inc.) Seaguard current meter at $23 \mathrm{~m}$ depth. Sampling interval was $1 \mathrm{~min}$ for all moored instruments. Time series of the depth of each instrument is inferred from the pressure record (the depth of the two Microcats without pressure sensors were interpolated from the adjacent sensors). The resulting time-depth structure of temperature and salinity is then gridded onto $20 \mathrm{~m}$ regular vertical spacing. This processing accounts for the mooring motion. With the exception of the Longranger that stopped after $15 \mathrm{~h}$ because of a leakage, all moored instruments sampled throughout the deployment.

Post-processing of the CTD and current measurements follows common procedures and is briefly summarized in F2010. Post-processing of the microstructure data follows Fer (2006), see also F2010. Profiles of dissipation rate of turbulent kinetic energy (TKE) per unit mass, $\varepsilon$, are obtained 
from the shear probes to a noise level of $5 \times 10^{-10} \mathrm{~W} \mathrm{~kg}^{-1}$. The reduced data set collected from the vessel and used in the analysis includes current profiles from the VM-ADCP (hourly temporal and $4 \mathrm{~m}$ vertical average) and XCPs ( $2 \mathrm{~m}$ vertical average), temperature, salinity and potential density anomaly, $\sigma_{\theta}$, profiles from the ship's CTD and from the MSS ( $1 \mathrm{~m}$ vertical average), and dissipation rate $\varepsilon$ from the MSS ( $1 \mathrm{~m}$ vertical average). The data set from the mooring includes hourly averaged and vertically gridded horizontal velocity and $\sigma_{\theta}$ profiles at 8 and $20 \mathrm{~m}$ vertical resolution, respectively.

\subsection{Numerical modelling}

The numerical model is a global high-resolution ocean circulation and tide model coupled to a thermodynamic seaice component (STORMTIDE, Müller et al., 2012). The STORMTIDE model is formulated on a global tripolar grid with an average horizontal resolution of about $10 \mathrm{~km}$, which becomes as small as $5 \mathrm{~km}$ in high latitudes. Thus, the mesoscale ocean circulation is implicitly resolved. There are 40 vertical $z$ levels and the time step of the numerical scheme is $600 \mathrm{~s}$, sufficient to simulate the low-mode internal tides. The model physics and numerics are based on the Max Planck Institute Ocean Model (Jungclaus et al., 2006). The astronomical tidal forcing is described by ephemerides and represents the complete lunisolar tidal forcing of second degree. The model uses no internal wave drag, i.e. no additional energy sink for barotropic tides in the deep ocean. The conversion of barotropic-to-baroclinic tidal energy (Sect. 3.1) amounts to $1.14 \mathrm{TW}\left(1 \mathrm{TW} \equiv 10^{12} \mathrm{~W}\right)$ in the deep ocean, and is in the range of previous estimates from models, theory, and observations (Egbert and Ray, 2000; Simmons et al., 2004; Nycander, 2005).

A 10-year STORMTIDE simulation is used in the present study, and a detailed description on the set-up of the model simulation including atmospheric forcing, restoring schemes, and physical parametrization can be found in Müller et al. (2014). The hourly output of 32 days of sea level and velocities, starting 1 January, has been used for a harmonic analysis with respect to several tidal constituents (Foreman et al., 2009). Global model products of tidal velocities, energetics, and sea level are available for download at the World Data Centre for Climate (see Müller et al., 2014, for details). The barotropic and low-mode internal tides have been evaluated in Müller et al. (2012). It has been shown that the surface signature of internal tide, evaluated by sea surface satellite products, is reasonably well captured. The barotropictide-induced sea level variability is captured to $93 \%$ and a recent barotropic tide model intercomparison shows that STORMTIDE ranks similar to other modern hydrodynamic tide models (Stammer et al., 2014).

\section{Methods of analysis}

In order to characterize the tidal forcing and energetics at the YP region and at the observation stations, the STORMTIDE and the cruise data, respectively, are used. The methods involved are summarized below. The analysis is based on the baroclinic perturbation fields (e.g. horizontal velocity and pressure) at tidal frequency which are obtained using harmonic analysis of the model and observational baroclinic perturbation fields. The baroclinic perturbations are indicated by a prime; purely sinusoidal baroclinic fluctuations generated using the harmonic analysis results are indicated by a tilde over the corresponding variable.

\subsection{Tidal energy conversion and baroclinic energy fluxes from STORMTIDE}

The simulated tidal energy flux and conversion of barotropicto-baroclinic tidal energy are computed from the model by using the derivations presented in Kang and Fringer (2012). The vertically integrated, barotropic-to-baroclinic tidal energy conversion rates are obtained from

$C=\langle\overline{g \widetilde{\rho} W}\rangle_{t}$,

where $\tilde{\rho}$ is the density perturbation associated with the tidal motion, $g$ the gravitational acceleration, and $\langle\cdot\rangle_{t}$ and the overbar denote averages in time and integral in the vertical, respectively. Using the model bottom topography and the barotropic tidal currents, the barotropic vertical velocity $W(z)$ at depth $z$ is defined as

$W(z)=\frac{z}{H}\left(\boldsymbol{u}_{\mathrm{BT}} \cdot \nabla_{\mathrm{H}} H\right)$,

where $H$ is the total water depth, $\nabla_{\mathrm{H}}$ is the horizontal differential operator, and $\boldsymbol{u}_{\mathrm{BT}}$ the horizontal barotropic tidal current vector.

The vertically integrated, baroclinic tidal energy flux with zonal and meridional components, $\boldsymbol{F}=\left(F_{u}, F_{v}\right)$, is calculated from

$\boldsymbol{F}=\langle\overline{\widetilde{p}(z, t) \widetilde{\boldsymbol{u}}(z, t)}\rangle_{t}$,

where $\widetilde{p}$ is the perturbation pressure associated with tidal motions and $\widetilde{\boldsymbol{u}}$ is the baroclinic tidal current vector, both obtained using harmonic analysis of the model output. At the latitudes of the YP, $\omega_{M_{2}}<f$ and the internal wave solution is evanescent (the horizontal wave number is imaginary and the group velocity, $\boldsymbol{c}_{\mathrm{g}}$, is zero). The common approach of relating $\widetilde{p} \widetilde{\boldsymbol{u}}$ to the baroclinic energy flux, $E \boldsymbol{c}_{\mathrm{g}}$ where $E$ is the energy density, should be interpreted with caution (see Sect. 3.3 for discussion). We further derive baroclinic radiation defined as the horizontal divergence of the baroclinic energy flux, $\nabla_{\mathrm{H}} \cdot \boldsymbol{F}$, and define the depth-integrated dissipation, $C-\nabla_{\mathrm{H}} \cdot \boldsymbol{F}$, as the difference between tidal energy conversion and radiation (e.g. Kang and Fringer, 2012). 


\subsection{Energy and energy flux from observations}

The calculation of the baroclinic energetics follows the common methods, see, e.g., Kunze et al. (2002) and Nash et al. (2005), and also accounts for isopycnal heaving by movement of the free surface (Kelly et al., 2010). For a sinusoidal wave, the calculation requires perturbation profiles of velocity and pressure isolated at the corresponding frequency band, sampled over the whole water column, for an integer number of wave periods. We apply harmonic analysis to determine the amplitude and phase of the lunar semidiurnal wave, generate full-period time series, and project them onto flat-bottom vertical modal shapes to obtain full-depth profiles at each station. Section 3.2.1-3.2.5 detail the methods involved in each step. The caveats associated with the flatbottom assumption and the limited time and vertical span of observations are discussed in Sect. 3.3. At all stations, density profiles are available for approximately two semidiurnal cycles (day-long time series). Comparably long velocity time series are obtained from VM-ADCP at stations 1, 2 , and 4 (Table 1). Stations 3 and 5, however, have too short VM-ADCP sampling duration to resolve the semidiurnal currents and are excluded from the analysis. At the mooring location near station 5, approximately full-depth, between 23 and $864 \mathrm{~m}$, and $15.1 \mathrm{~h}$ long current profiles recorded by the moored instruments allow for energy flux calculations.

\subsubsection{Baroclinic perturbation calculations}

Using the observed velocity and density profiles, baroclinic perturbation fields of velocity, $\boldsymbol{u}^{\prime}$, and buoyancy, $b$, are calculated similar to the methods described in Kunze et al. (2002) and Nash et al. (2005). The calculation of baroclinic pressure requires cumulative full-depth integrals, and is deferred to Sect. 3.2.5.

Baroclinic perturbation velocity, $\boldsymbol{u}^{\prime}$, is calculated by removing the depth-averaged velocity profile at each time and then removing the time average at each depth; $\boldsymbol{u}^{\prime}(z, t)=$ $\boldsymbol{u}(z, t)-\langle\boldsymbol{u}(z, t)\rangle_{z}-\langle\boldsymbol{u}(z, t)\rangle_{t} \cdot\langle\cdot\rangle_{z}$ and $\langle\cdot\rangle_{t}$ indicate averaging over depth and time, respectively. The depth average is an approximation to the barotropic velocity, and is valid because the frictional surface and bottom boundary layers are not covered by the moored instruments and the VM-ADCP. Vertical isopycnal displacement profiles, $\xi(z, t)$, are constructed using displacements of isopycnals from their station timemean depth. For the mooring data, displacements are calculated relative to $24 \mathrm{~h}$ moving average density profiles. The measured buoyancy perturbation is $b=-\left(g / \rho_{0}\right)\left(\sigma_{\theta}-\left\langle\sigma_{\theta}\right\rangle_{t}\right)$. Equivalent results are obtained using the vertical displacement, $\xi=-b N^{-2}$, where $N(z)=\left[-\left(g / \rho_{0}\right)\left(\partial\left\langle\sigma_{\theta}\right\rangle_{t} / \partial z\right)\right]^{1 / 2}$ is the buoyancy frequency.

\subsubsection{Semidiurnal fits}

In order to infer the baroclinic semidiurnal energy flux, we isolate the semidiurnal band using harmonic analysis. The semidiurnal frequency, $\omega_{M_{2}}=1.405 \times 10^{-4} \mathrm{~s}^{-1}$, and the inertial frequency at $80^{\circ} \mathrm{N}, f=1.44 \times 10^{-4} \mathrm{~s}^{-1} \sim 1.025 \omega_{M_{2}}$, cannot be distinguished because of short record length. Therefore, semidiurnal must be understood as the nearinertial band when discussing observations. However, in the period spanning the cruise and 4 weeks prior to the cruise, wind forcing in the region was weak (quantified and discussed in Sect. 3.3), and we do not expect significant contribution from wind-induced near-inertial waves.

The semidiurnal fluctuation $\widetilde{x}_{M_{2}}$ of a perturbation variable $x^{\prime}$ is estimated using harmonic analysis:

$\tilde{x}_{M_{2}}(z, t)=\left\langle x^{\prime}\right\rangle_{\mathrm{t}}+x_{M_{2}}(z) \cos \left(\omega_{M_{2}} t-\phi_{M_{2}}^{x}(z)\right)$

by minimizing the residual $R(z, t)$ in a least-square sense to determine the coefficients in

$x^{\prime}(z, t)=A(z) \cos \left(\omega_{M_{2}} t\right)+B(z) \sin \left(\omega_{M_{2}} t\right)+R(z, t)$,

where the amplitude profile is $x_{M_{2}}(z)=\left(A^{2}+B^{2}\right)^{1 / 2}$ and the phase profile is $\phi_{M_{2}}^{x}(z)=\arctan (B / A)$. The harmonic analysis is applied to $\boldsymbol{u}^{\prime}, b$, and $\xi$. Semidiurnal fits for the horizontal velocity components explain $30-90 \%$ of the total variance at the stations, whereas the semidiurnal vertical displacement accounts for relatively less (15-65\%) of the observed variance.

When the harmonic analysis is repeated using two constituents $\left(\omega_{K_{1}}=7.292 \times 10^{-5} \mathrm{~s}^{-1}\right.$ and $\left.\omega_{M_{2}}\right)$ for the stations with sufficiently long time series, the variance explained by $M_{2}$ is within $5 \%$ of the values obtained using the $M_{2}$ constituent only (much less than the uncertainty we assigned to harmonic analysis; see Sect. 3.3). At stations 1 and 2, where there are long enough VM-ADCP data to fit both constituents, $K_{1}$ accounts for $20-25 \%$ of the horizontal velocity. Diurnal vertical displacement accounts for $20-40 \%$ at stations $1-4$ and dominate $(57 \%)$ at station 5 . The diurnal component is clearly important at the YP. Because of the short station durations, we do not report diurnal baroclinic fluxes from the observations, but discuss them using the STORMTIDE model results.

\subsubsection{Vertical modes}

Constructed full-period baroclinic semidiurnal time series are used to derive full-depth profiles of $\widetilde{\boldsymbol{u}}, \widetilde{\xi}$, and $\widetilde{b}$. At each time, the corresponding vertical profile is projected onto orthogonal vertical modes with vertical structure $G_{j}$ of each mode $j$ governed by (Phillips, 1977)

$$
\frac{\mathrm{d}^{2} G_{j}(z)}{\mathrm{d} z^{2}}+\left[\frac{N^{2}(z)}{c_{j}^{2}}\right] G_{j}(z)=0,
$$


where $c_{j}$ is the eigenspeed for mode $j$. Vertical velocity and vertical displacement structures of each mode scale with $G_{j}$, while the horizontal velocity is proportional to $\mathrm{d} G_{j} / \mathrm{d} z$. Equation (4) is solved numerically for each station, using the station mean $N^{2}(z)$ and the boundary conditions $G_{j}(-H)=$ $G_{j}(0)=0$, where $H$ is the total depth. Modal amplitudes are then obtained by least-squares fitting (stable solutions are obtained for the first three baroclinic modes). The fulldepth profiles are constructed as the sum over modes as, for example, $\widetilde{\boldsymbol{u}}(z, t)=\sum \boldsymbol{U}_{j}(t) \mathrm{d} G_{j}(z) / \mathrm{d} z$, where $\boldsymbol{U}_{j}$ is the amplitude of the horizontal velocity for mode $j$. When averaged over each station's duration, the first three modes account for $50-80 \%$ of the semidiurnal baroclinic velocity and $30-65 \%$ of the semidiurnal isopycnal displacement. Vertical modes are orthogonal only over the full depth and over flat bottom. For steep slopes (relative to the wave slope), the horizontal and vertical structures cannot be separated and modal coupling may occur. The associated error in our analysis is discussed in Sect. 3.3.

\subsubsection{Wentzel-Kramers-Brillouin scaling}

Although the stations are closely spaced, the stratification differs significantly as a result of lateral gradients in proximity to the ice edge (see F2010). In order to account for the varying stratification, we apply Wentzel-Kramers-Brillouin (WKB) scaling (Leaman and Sanford, 1975) using the survey mean stratification of $N_{0}=2.4 \times 10^{-4} \mathrm{~s}^{-1}$ as the reference buoyancy frequency. The stretched depth for a given station mean $N(z)$ profile is $z_{\mathrm{wkb}}=\int_{z}^{0} N\left(z^{\prime}\right) / N_{0} \mathrm{~d} z^{\prime}$. Horizontal velocity and pressure scale as $\left(N_{0} / N(z)\right)^{1 / 2}$, and vertical velocity and displacement scale as $\left(N(z) / N_{0}\right)^{1 / 2}$. Table 1 lists the stretched water depth and the percentage of the stretched water column covered by the instruments. Although the sampling was limited to the upper $520 \mathrm{~m}$ (MSS) and $360 \mathrm{~m}$ (VMADCP), 64-99\% (MSS) and 49-73\% (VM-ADCP) of the stretched water column were covered. The portion of the mooring densely equipped with the Microcats covers $75 \%$ of the stretched depth.

\subsubsection{Energy and energy flux calculations}

Full-depth and full-period baroclinic semidiurnal fields $\widetilde{\boldsymbol{u}}$ and $\widetilde{b}$ are constructed as the sum of the first three baroclinic modes. Baroclinic horizontal kinetic energy (HKE) and available potential energy (APE) in units of $\mathrm{J} \mathrm{m}^{-3}$ are obtained from

$$
\begin{aligned}
& \operatorname{HKE}(z)=\frac{\rho_{0}}{2}\left\langle\widetilde{u}(z, t)^{2}+\widetilde{v}(z, t)^{2}\right\rangle_{t}, \\
& \operatorname{APE}(z)=\frac{\rho_{0}}{2} N(z)^{-2}\left\langle\widetilde{b}(z, t)^{2}\right\rangle_{t},
\end{aligned}
$$

where $N(z)$ is the station-mean buoyancy frequency profile (calculated using the time-averaged density profile, $\left\langle\sigma_{\theta}\right\rangle_{t}$ ). The vertically integrated horizontal baroclinic energy flux,
$\boldsymbol{F}$, is obtained from Eq. (3). The internal tide baroclinic pressure perturbation, $\widetilde{p}$, in units of $\mathrm{Pa}$, is calculated using hydrostatic assumption and following Kelly et al. (2010) as

$\widetilde{p}(z, t)=\int_{z}^{0} \rho_{0}\left(\widetilde{b}-b^{\eta}\right) \mathrm{d} z^{\prime}-c$,

where $\rho_{0}$ is the reference density and $c$ is a constant of integration that ensures $\widetilde{p}$ has zero depth average. The second term in Eq. (6) is buoyancy due to isopycnal heaving by movement of the free surface,

$b^{\eta}=-N^{2} \eta\left(\frac{z+H}{H}\right)$,

where $\eta$ is the surface displacement (Kelly et al., 2010). We use $\eta$ from STORMTIDE at the observation station locations. When the pressure perturbation induced by the isopycnal heaving by movement of the free surface is ignored, calculations of Kelly et al. (2010) indicate $10-50 \mathrm{~W} \mathrm{~m}^{-1}$ error in depth-integrated baroclinic energy fluxes, negligible over the energetic Kaena Ridge in Hawaii, but amounting to 10-45\% error over the Oregon continental slope.

\subsection{Errors, uncertainty, and caveats}

Observations suffer from short sampling duration, and from the uncertainty propagated from modal fits to vertically gappy sampling. Furthermore, in the analysis of the observations there are errors as a result of the study site that is characterized by topography (modal analysis assumes flat bottom) and high latitude (near-inertial waves are in the semidiurnal band). The analysis of the STORMTIDE model data is free from these errors because modal analysis is not employed, and the inertial and tidal frequencies are delineated by the harmonic analysis of sufficiently long time series.

Errors and systematic bias in baroclinic energy flux calculations for a variety of oceanographic sampling schemes are discussed thoroughly in Nash et al. (2005). Using Monte Carlo simulations of synthetic data, including a combination of semidiurnal, near-inertial and internal wave continuum signal, they assess magnitude and parameter dependence of flux estimates made from temporally or vertically imperfect data. For large baroclinic semidiurnal energy fluxes, such as those near a generation site in Hawaiian Ridge, a set of six full-depth profiles spanning $15 \mathrm{~h}$ leads to unbiased estimates of semidiurnal depth-integrated energy flux with $10 \%$ error. Even for much weaker fluxes, the error is about $25 \%$, which is representative of our XCP sampling at station 1 with six casts spanning $20 \mathrm{~h}$. The error further decreases with increasing number of profiles collected in a tidal period. Our shipboard sampling is typically 20-26 profiles (MSS and hourly averaged VM-ADCP) spanning two semidiurnal cycles; hence, errors associated with the harmonic analysis are expected to be small. The analysis of Nash et al. (2006), however, ignores the possible contamination of the semidiurnal 
band by the inertial waves at high latitudes. Inertial motions in the upper mixed layer are typically excited by energetic wind events and only a small fraction of the energy propagates deeper into the water column as near-inertial waves (see e.g. Alford et al., 2012). Short time series at our stations can be contaminated by near-inertial wave signals generated previous to the cruise at distant poleward locations. During the period 25 June-2 August 2007, spanning the cruise period and 4 weeks prior to the cruise, average ERA-Interim $10 \mathrm{~m}$ height wind speed using all grid points within a $100 \mathrm{~km}$ radius from station 2 is $5 \mathrm{~m} \mathrm{~s}^{-1}$, with only $4 \%$ stronger than $10 \mathrm{~m} \mathrm{~s}^{-1}$, and none stronger than $12 \mathrm{~m} \mathrm{~s}^{-1}$. We therefore do not expect significant contribution from wind-induced nearinertial waves. Considering the competing effects of weak baroclinic energy fluxes (more error) and more than six profiles per analysis period (less error), and an unquantified but small contamination from near-inertial waves, we assign $20 \%$ error to harmonic analysis.

For the case of vertically gappy sampling, Nash et al. (2005) find that larger gaps can be tolerated near the bottom after WKB scaling (as in the case of our MSS and VMADCP sampling), but estimates are sensitive to the data near the surface. Because the energy flux scales as the buoyancy frequency, it is typically surface intensified. For a two-mode fit, when only the top $30 \%$ of the WKB-stretched water column is sampled, Nash et al. (2006) inferred less than $40 \%$ error in $\boldsymbol{F}$. Using the XCP data (approximately full-depth profiles), we attempt to estimate the error associated with the limited vertical extent of our station data sets. We repeat the XCP-station analysis using the portion of the velocity measurements between 12 and $360 \mathrm{~m}$ depth, identical to the VMADCP coverage, and the CTD profiles between 3 and $500 \mathrm{~m}$ depth, identical to the MSS coverage. Relative to the fulldepth analysis, error in the depth-averaged HKE and APE is 7 and $100 \%$, respectively. The latter is a result of poor modal fits when the lower half of the water column is not sampled. The depth-integrated baroclinic energy flux error is $52 \%$, comparable to the error reported by Nash et al. (2005).

Our modal decomposition has errors as a result of imperfect depth coverage and sloping bottom. Modes are orthogonal only over the full water depth and over flat bottom, and contamination arises when unresolved variance is projected onto resolved modes, or when the horizontal and vertical structure cannot be separated over steep topography. The error associated with modal analysis can be estimated using the station 4 data. This station has the best vertical coverage and the energetics can be inferred using the observed profiles without modal analysis. The profiles of density cover approximately the entire water column (Table 1), crucial for pressure anomaly calculations. We repeat the station 4 analysis, but without fitting to the modal shapes. The error will thus include both the effect of sloping bottom and the unresolved higher vertical modes. Relative to results without modal fits, error in the depth-averaged HKE and APE is 34 and $36 \%$, respectively. The depth-integrated baroclinic energy flux error is $48 \%$.

The errors estimated for each source (harmonic analysis, imperfect vertical sampling, and projection onto flat-bottom normal modes), are not entirely independent, and are not the same for each station. Overall, we assign total errors of $50 \%$ to HKE and $100 \%$ to APE and $\boldsymbol{F}$.

At the latitudes of the YP diurnal and lunar semidiurnal, internal waves are evanescent with zero group velocity, and our calculations (for both the observations and the model data), using the common approach of $E \boldsymbol{c}_{\mathrm{g}}=\tilde{p} \widetilde{\boldsymbol{u}}$, should be interpreted with caution. The water column is not a solid boundary, and forced internal waves in the water column will leak their energy from the generation site to only a limited vertical and lateral extent. Trapped sub-inertial baroclinic motions, however, are also possible and may propagate along the topographic contours (several examples are cited in Sect. 6). Our results thus represent the baroclinic fluxes in a given frequency band, induced by pressure and velocity perturbations associated with tidal response over topography, with possible leaking internal waves and trapped waves.

The STORMTIDE model results are obtained from a global model which has, from a regional perspective, a rather coarse resolution. The model is hydrostatic and thus only permits internal waves with frequencies much less than the buoyancy frequency, which is a reasonable limit for the semidiurnal waves. The horizontal resolution restricts the model to resolve only the low-mode internal tides. The model results are limited to interpretation for linear wave characteristics. The global model thus can not compete with regional models resolving non-linear characteristics of internal wave propagation (e.g. Simmons et al., 2011). However, due to its global characteristics it explicitly avoids the boundary condition issue, which is critical for concurrent simulations of mesoscale ocean circulation and internal tides. The dissipation of internal waves results from numerical parametrization of bottom friction and eddy viscosity and further by numerical dissipation. Previous evaluations against observations from satellite altimetry (Müller et al., 2012), tide gauges (Müller et al., 2014), and a detailed comparison of the generation of internal tides with observations, theory, and inverse models (Müller, 2013) support with confidence that the model simulated internal tides inherit some degree of realism: the internal wave generation and propagation of internal tides are reasonably well represented; near generation sites in the deep ocean, the magnitude of the surface signature of internal tides is reasonably well reproduced; and the magnitudes and the regional characteristics of barotropic-tobaroclinic tidal conversion rates compare well with those in other models, and observational and theoretical studies. 


\section{Variability at the observation stations}

Observations in 2007 were made during neap and transition to spring tides (Fig. 2). The data show strong variability in velocity and vertical isopycnal displacement in both diurnal and semidiurnal bands. Tidal surface elevation inferred at the model grid point nearest to the mooring location shows a tidal range of up to $\pm 0.5 \mathrm{~m}$, and both its phase and magnitude agree with the record inferred from the moored pressure sensor nearest to the seabed (Fig. 2a), lending further confidence on the model output. The duration of the current record is short; however, the depth-average current agrees well with the tidal flow. A detailed comparison is not attempted since we cannot infer all four tidal constituents $\left(M_{2}, S_{2}, K_{1}, O_{1}\right)$ from the $15.1 \mathrm{~h}$ long ADCP record. The time-depth maps of the vertical isopycnal displacement recorded by the moored instruments show up to $\pm 40 \mathrm{~m}$ alternating bands with mixed diurnal and semidiurnal periodicity. On the southern flanks of the plateau, tidal ellipses derived from STORMTIDE show comparably strong semidiurnal $\left(M_{2}\right)$ and diurnal $\left(K_{1}\right)$ currents (not shown). At the observation site, STORMTIDE tidal current amplitudes at station 2 (the most energetic station for all constituents) are $\left(K_{1}, O_{1}, M_{2}, S_{2}\right)=(13,6,14$, 5) $\mathrm{cm} \mathrm{s}^{-1}$; i.e. semidiurnal and diurnal bands are of comparable magnitude and typically $K_{1}$ and $M_{2}$ dominate over $O_{1}$ and $S_{2}$. Frequency spectra of total velocity at the pycnocline presented in F2010 correspond to about 3 times larger HKE in the diurnal band compared to the semidiurnal band. In agreement with the velocity spectrum, the diurnal band is the most energetic in the vertical isopycnal displacement spectra throughout the water column at the mooring location (F2010). Consistently, depth-integrated baroclinic energy fluxes from STORMTIDE averaged within $10 \mathrm{~km}$ of the mooring location (station 5) are dominated by $K_{1}$ (Sect. 5; Table 4).

An overview of the semidiurnal amplitudes obtained from the harmonic analysis of the horizontal current and isopycnal displacements at stations 1, 2, and 4 is given in Fig. 3. A detailed model-observation comparison is not attempted; however, the observed semidiurnal amplitudes generally compare well with the STORMTIDE results. Station 2 has baroclinic semidiurnal amplitudes comparable to the barotropic tide, whereas at the other stations the barotropic component is larger. The observed barotropic current amplitude of approximately $5 \mathrm{~cm} \mathrm{~s}^{-1}$ at station 2 is significantly less than the $M_{2}$ amplitude from STORMTIDE mentioned above. Overall, the baroclinic semidiurnal current amplitudes are weak; nevertheless, the semidiurnal signal accounts for a significant percentage of the observed profiles (Sect. 3.2.2). The amplitudes are comparable to those from a numerical modelling study of the Barents Sea that show less than $5 \mathrm{~cm} \mathrm{~s}^{-1}$ semidiurnal baroclinic velocity at intermediate depths (Kagan and Sofina, 2014). For comparison, trapped baroclinic diurnal current amplitudes off the southern California Bight (Johnston and Rudnick, 2014) are typically 2-3 times more energetic
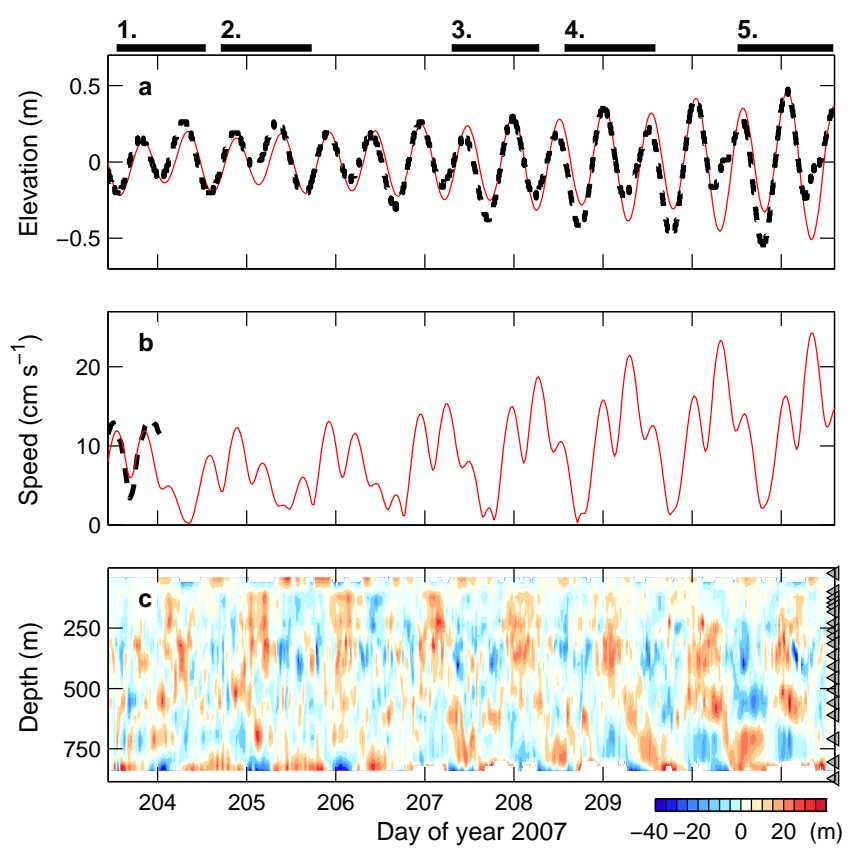

Figure 2. Time series at station 5 of (a) tidal surface elevation from STORMTIDE (red; sum of 8 major constituents) and near-bottom pressure anomaly from the deepest moored instrument (dashed), (b) tidal current from STORMTIDE (red; sum of $M_{2}, K_{1}, S_{2}$ and $O_{1}$ ) and depth-averaged current measured by the moored instruments (dashed), and (c) vertical isopycnal displacements. The downloaded archived STORMTIDE global data set is limited to these four major constituents for the tidal velocity and phase. The time-average depth of the instruments are shown by triangles on the right. Bars on top show the duration of stations $1-5$.

than the semidiurnal current amplitudes at our YP stations. On the northern part of the YP, where the major barotropicto-baroclinic energy conversion sites are located, larger amplitudes are modelled (Sect. 5). At station 1, baroclinic vertical displacement is typically less than the barotropic component. In the upper $150 \mathrm{~m}$ of stations 2 and 4 and between 200 and $300 \mathrm{~m}$ at station 4 , baroclinic vertical displacement exceeds the barotropic contribution. The phase of the horizontal current increases approximately linearly with depth at station 1 , indicating upward energy propagation with a vertical wavelength of at least $500 \mathrm{~m}$. This is supported by the vertical wave number spectra obtained for the bottommost $512 \mathrm{~m}$ of the full-depth shear profiles sampled by XCPs suggesting upward energy propagation (F2010). The phase of the vertical displacement, on the contrary, typically decreases with depth. This can be a consequence of the sub-inertial semidiurnal waves trapped along the topography. At stations 2 and 4 , phase profiles show $180^{\circ}$ jumps suggesting a vertically standing behaviour.

Observed baroclinic energetics inferred from full-depth profiles for the sum of the first three modes are summarized in Table 2. The ratio $R$ of depth-averaged HKE to APE varies 

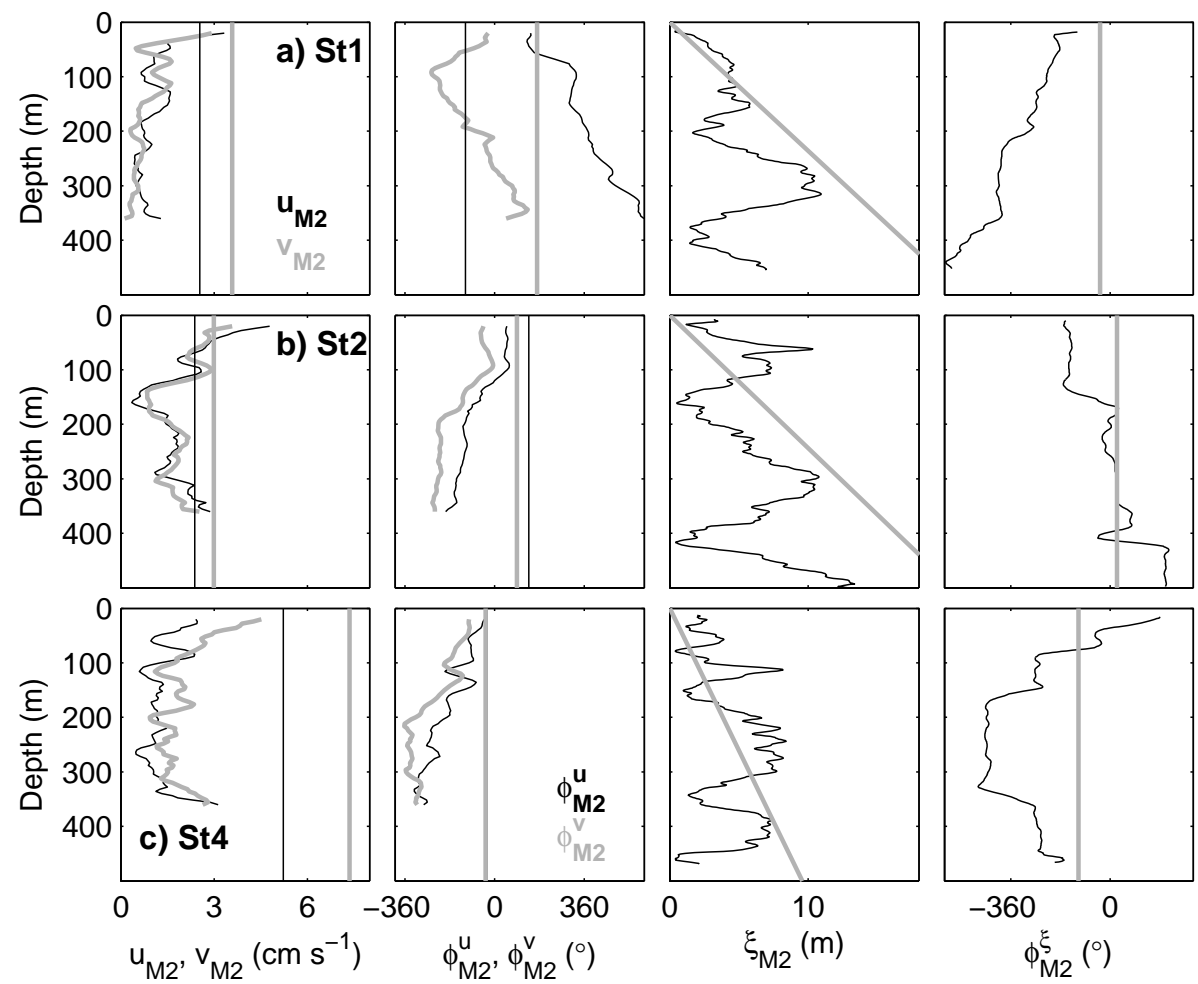

Figure 3. Profiles of amplitude and phase of baroclinic $u$, $v$, and $\xi$ obtained from the semidiurnal fits to VM-ADCP and MSS profiles at stations (a) 1, (b) 2, and (c) 4. Also shown are the corresponding barotropic amplitude (vertical lines for $u$ and $v$, and slanted lines for $\xi$ ) and phase (vertical lines), inferred from identical harmonic analysis of the depth-averaged currents and profile of barotropic displacement.

Table 2. Semidiurnal baroclinic energetics at observation stations. Results are shown for the sum of the first three baroclinic modes. An overbar indicates integration over depth; 1 -XCP is station 1 with results obtained from the XCP profiles; 5-M is the mooring located near station 5 .

\begin{tabular}{lrrrrrrr}
\hline Station & $\begin{array}{r}10^{3} \times \mathrm{HKE} \\
\left(\mathrm{J} \mathrm{m}^{-3}\right)\end{array}$ & $\begin{array}{r}10^{3} \times \mathrm{APE} \\
\left(\mathrm{J} \mathrm{m}^{-3}\right)\end{array}$ & $R$ & $\begin{array}{r}\overline{\mathrm{HKE}} \\
\left(\mathrm{J} \mathrm{m}^{-2}\right)\end{array}$ & $\begin{array}{r}\overline{\mathrm{APE}} \\
\left(\mathrm{J} \mathrm{m}^{-2}\right)\end{array}$ & $\begin{array}{r}F_{u} \\
\left(\mathrm{~W} \mathrm{~m}^{-1}\right)\end{array}$ & $\begin{array}{r}F_{v} \\
\left(\mathrm{~W} \mathrm{~m}^{-1}\right)\end{array}$ \\
\hline $1-\mathrm{XCP}$ & $211 \pm 106$ & $41 \pm 41$ & $5 \pm 5$ & $205 \pm 103$ & $25 \pm 25$ & $-29 \pm 29$ & $41 \pm 41$ \\
1 & $143 \pm 72$ & $56 \pm 56$ & $3 \pm 3$ & $142 \pm 71$ & $33 \pm 33$ & $-20 \pm 20$ & $21 \pm 21$ \\
2 & $87 \pm 44$ & $22 \pm 22$ & $4 \pm 4$ & $84 \pm 42$ & $12 \pm 12$ & $-14 \pm 14$ & $8 \pm 8$ \\
3 & - & $97 \pm 97$ & - & - & $70 \pm 70$ & - & - \\
4 & $80 \pm 40$ & $15 \pm 15$ & $5 \pm 5$ & $50 \pm 25$ & $8 \pm 8$ & $-2 \pm 2$ & $-3 \pm 3$ \\
5 & - & $39 \pm 39$ & - & - & $20 \pm 20$ & - & - \\
$5-\mathrm{M}$ & $315 \pm 158$ & $47 \pm 47$ & $7 \pm 7$ & $148 \pm 74$ & $12 \pm 12$ & $-4 \pm 4$ & $15 \pm 15$ \\
\hline
\end{tabular}

between 3 and 7, but with $100 \%$ error bars. $R$ is equivalent to the shear-strain ratio $R_{\omega}$ discussed in F2010. The values up to 14 , when a factor of 2 uncertainty is considered, are typical in the ocean and are consistent with the values inferred in F2010. Estimates from the XCP data at station 1 are larger than those from the MSS/VM-ADCP profiles (but within the error bars), suggesting that the lack of MSS/VMADCP sampling in the deepest $50 \%$ of the stretched depth affects the results. The horizontal components of the depthintegrated $M_{2}$ baroclinic energy flux are listed in Table 2. At stations 1 and $5, \boldsymbol{F}$ is directed nearly along the isobaths. The largest $\boldsymbol{F}$ is observed at station 1 on the western flank. The results are similar when derived from the MSS/VM-ADCP profiles or from the XCP profiles.

The measurements of the dissipation rate will be used in Sect. 6 to characterize the typical volume-integrated dissipation levels in the YP region. A station-mean profile of dissipation rate $\varepsilon$ measured by the microstructure profiler is obtained by averaging over all profiles collected at each station (Fig. 4). Depth-integrated dissipation rates are given in Table 3. Station 4 has the largest dissipation rates. Station 4 profile extends to the bottom; observations at other 
Table 3. Depth-integrated dissipation rate at observation stations in units of $10^{-3} \times \mathrm{W} \mathrm{m}^{-2}$. Integrations down to $500 \mathrm{~m}$ are obtained from the station mean $\varepsilon$ profiles. Integrations from $50 \mathrm{~m}$ to the bottom use the assumed minimum and maximum $\varepsilon$ profiles described in the text.

\begin{tabular}{ccccc}
\hline Station & $\int_{0}^{500 \mathrm{~m}} \rho \varepsilon \mathrm{d} z$ & $\int_{50 \mathrm{~m}}^{500 \mathrm{~m}} \rho \varepsilon \mathrm{d} z$ & $\int_{50 \mathrm{~m}}^{H} \rho \varepsilon_{\min } \mathrm{d} z$ & $\int_{50 \mathrm{~m}}^{H} \rho \varepsilon_{\max } \mathrm{d} z$ \\
\hline 1 & 3.7 & 0.4 & 0.3 & 1.0 \\
2 & 2.3 & 0.6 & 0.7 & 1.2 \\
3 & 0.8 & 0.5 & 0.6 & 1.3 \\
4 & 1.9 & 1.3 & 1.3 & 1.3 \\
5 & 0.9 & 0.3 & 0.2 & 0.7 \\
\hline
\end{tabular}

stations, however, are limited to $500 \mathrm{~m}$ depth. Because the turbulence near the surface layer can be dominated by other processes than internal wave-induced mixing, values integrated between 50 and $500 \mathrm{~m}$ depth are also listed in Table 3. In order to have an estimate of the full-depth (below $50 \mathrm{~m}$ ) integrated $\varepsilon$ for all stations, we construct a lower bound $\left(\varepsilon_{\min }\right)$ and an upper bound $\left(\varepsilon_{\max }\right)$ profile down to the mean echo depth of each station. Profiles of $\varepsilon_{\max }$ are obtained by extending the $450-500 \mathrm{~m}$ average value to $100 \mathrm{~m}$ height above seabed, and thereafter exponentially increasing this value by a factor of 10 until the bottom is reached (Fig. 4). The near-bottom enhancement for $\varepsilon_{\max }$ is applied to account for bottom boundary turbulence and breaking of internal waves over the slope. The profiles of $\varepsilon_{\min }$ are constructed by extending the observed profiles by an assumed low dissipation of $10^{-10} \mathrm{~W} \mathrm{~kg}^{-1}$. Observed profiles at stations 1 and 5 reach the noise level of $5 \times 10^{-10} \mathrm{~W} \mathrm{~kg}^{-1}$ below about $150 \mathrm{~m}$, suggesting that actual values can be lower. We therefore exponentially reduce the $450-500 \mathrm{~m}$ average value for stations 2 and 3 , and the value at $200 \mathrm{~m}$ for stations 1 and 5 , to $10^{-10} \mathrm{~W} \mathrm{~kg}^{-1}$ over a $200 \mathrm{~m}$ vertical scale, and extend this value to the seabed (Fig. 4). Depth-integrated dissipation below the surface mixed layer is typically between 0.2 and $1.3 \times 10^{-3} \mathrm{~W} \mathrm{~m}^{-2}$, with largest values at station 4 . Limited by the ice edge, our observations were made only on the southern part of the YP. On the one hand, these stations are not as energetic as the significant conversion sites on the northern flanks. On the other hand, the dissipation rate profiles do cover several regimes (the quiescent station 1, the moderately turbulent station 2, and the turbulent station 4). Using the constructed dissipation profiles described above, we are confident that we obtain lower and upper bounds on the dissipation rate representative of the YP.

\section{Energetics from the model}

Barotropic tidal fluxes inferred from STORMTIDE are shown in Fig. 5. These can be compared to the $K_{1}$ and $M_{2}$ tidal fluxes around Svalbard shown in Chen et al. (2009): the limited region shown in Fig. 5 is part of a pattern in which the $M_{2}$ energy propagates clockwise around the Svalbard is-

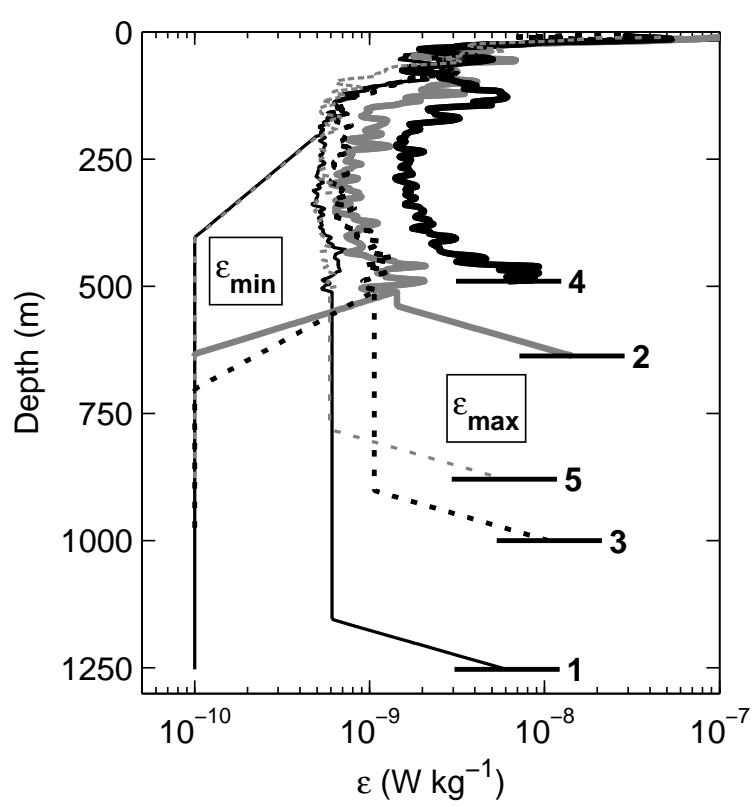

Figure 4. Dissipation rate profiles for stations 1-5. Horizontal lines with the station number indicated mark the mean echo sounder depth for the station. Observed, station-mean profiles are shown in the upper $500 \mathrm{~m}$. Assumed full-depth profiles used in calculating depth-integrated $\varepsilon$ are shown for the lower bound $\varepsilon_{\min }$ and the upper bound $\varepsilon_{\max }$.

lands, whereas the $K_{1}$ tidal energy is mainly trapped along the steep bottom topography. Both the $K_{1}$ and $M_{2}$ tidal fluxes are elevated along the shelf break north of Spitsbergen and also along the outer flank of the plateau, particularly close to the CEAREX-O camp drift site. These regions of large barotropic fluxes are also associated with high conversion rates and depth-integrated baroclinic fluxes (Fig. 6).

The depth-integrated baroclinic fluxes in the energetic parts of the YP are on the order of $200 \mathrm{~W} \mathrm{~m}^{-1}$ for $M_{2}$ and $1000 \mathrm{~W} \mathrm{~m}^{-1}$ for $K_{1}$. Near our mooring location, the depthintegrated energy flux is 1 order of magnitude smaller than at many of these energetic sites, and is reduced by another order of magnitude at the other stations.

Barotropic-to-baroclinic energy conversion rate, $C$, is shown for the semidiurnal and the diurnal tide in Fig. 6. The CEAREX-O site is characterized by moderate $M_{2}$ but substantially larger $K_{1}$ conversion rates, reaching $0.05 \mathrm{~W} \mathrm{~m}^{-2}$; the fluxes echo this pattern. The model results are thus consistent with the observations from the CEAREX-O camp where energetic internal waves and enhanced mixing were measured (Padman and Dillon, 1991). Negative conversion rates seen in Fig. 6 are typical of numerical studies on internal tide energetics (Simmons et al., 2004; Kang and Fringer, 2012). A negative conversion occurs when energy is transferred from baroclinic tide to the barotropic tide and indicates interaction between locally and remotely generated baroclinic tides. Relatively large semidiurnal baroclinic fluxes 


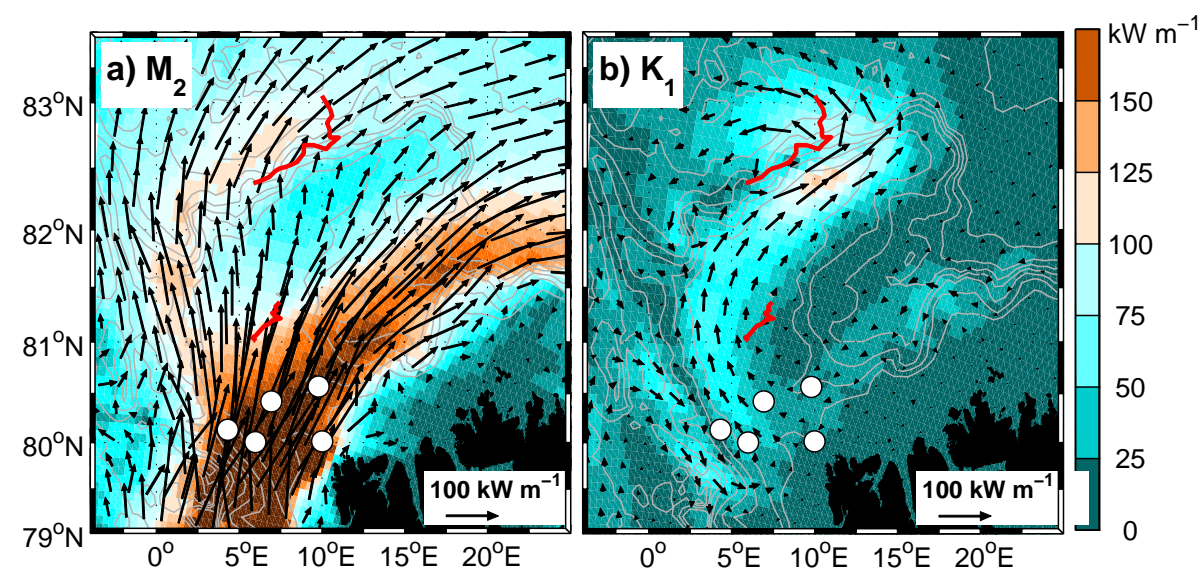

Figure 5. Barotropic tidal flux obtained from STORMTIDE for the (a) $M_{2}$ and (b) $K_{1}$ constituents. Isobaths (grey) are drawn at $500 \mathrm{~m}$ intervals from the model topography. The colour is the amplitude of the corresponding flux with colour bar on the right. Every fourth vector is shown with scale indicated. Station positions (open circles), and the drift of CEAREX-O (Padman and Dillon, 1991) (red line over the northern flank) and MIZEX83 (D’Asaro and Morison, 1992) (red line over the plateau) are shown for reference.
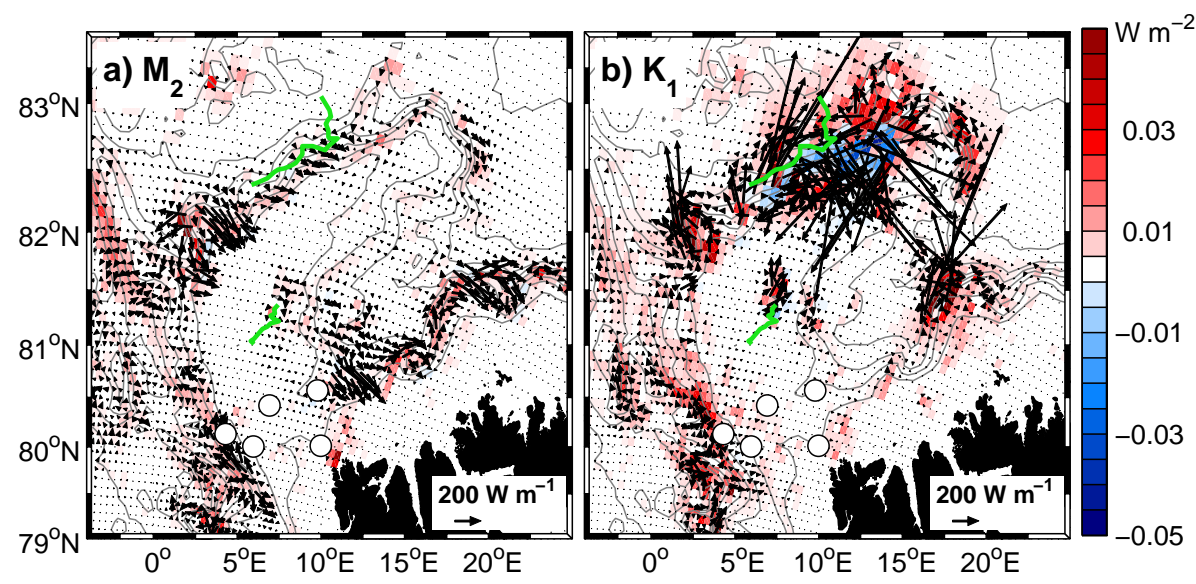

Figure 6. Barotropic-to-baroclinic conversion rate (colour) and the depth-integrated baroclinic energy fluxes (arrows) obtained from STORMTIDE for the (a) $M_{2}$ and (b) $K_{1}$ constituents. Isobaths (grey) are drawn at $500 \mathrm{~m}$ intervals from the model topography. Station positions (open circles) and the drift of CEAREX-O (Padman and Dillon, 1991) and MIZEX83 (D'Asaro and Morison, 1992) (green) are shown for reference.

can be observed on the western part of the plateau around $82^{\circ} \mathrm{N}$, and also along the shelf break north of Spitsbergen. Fluxes are typically directed along the topography and with a limited lateral extent consistent with trapped tides.

The site of observational stations is characterized by weak conversion rates and depth-integrated baroclinic fluxes, $\boldsymbol{F}$, except near stations 1 and 5 on the western slope. From the model, $\boldsymbol{F}$ is calculated as the average over grid points within $10 \mathrm{~km}$ in the vicinity of each station. The results, together with 1 standard deviation, are listed in Table 4 for the major diurnal and semidiurnal constituents. The variability at neighbouring grid points is large. The $M_{2}$ and $K_{1}$ constituents are comparable in magnitude and are greater than the $S_{2}$ and $O_{1}$ fluxes. The fluxes inferred from the observations (for $M_{2}$ only) compare fairly well with the model results when averaged in the vicinity of the station location (compare Tables 2 and 4); however, the comparison is poor when a single data point from the nearest grid to the station is used. Observed flux vectors are smaller than the size of the station markers in Fig. 6a; hence, they are not shown (a direct comparison on map is presented in Sect. 6).

The conversion rates in the vicinity of the stations are dominated by the $M_{2}$ and $K_{1}$ constituents (3-10 times larger than $S_{2}$ and $O_{1}$ ), with values between 1 and $10 \times 10^{-3} \mathrm{~W} \mathrm{~m}^{-2}$, and with largest rates near station 1 . Model dissipation rates at the station positions are weak, similar for $M_{2}$ and $K_{1}$, and vary between an order of $10^{-3} \mathrm{~W} \mathrm{~m}^{-2}$ (station 2) and an order of $10^{-2} \mathrm{~W} \mathrm{~m}^{-2}$ (station 1). These can be compared to the observed values of order $10^{-3} \mathrm{~W} \mathrm{~m}^{-2}$ shown in Table 3 . The observational stations are limited to the relatively less 
Table 4. Depth-integrated baroclinic fluxes, $\boldsymbol{F}$, in units of $\mathrm{W} \mathrm{m}^{-1}$ inferred from STORMTIDE using the grid points within $10 \mathrm{~km}$ of the observation stations. The average $\pm 1 \mathrm{SD}$ over the corresponding grid points are listed for the horizontal components $\left(F_{u}, F_{v}\right)$ of the four major constituents.

\begin{tabular}{lrrrr}
\hline Station & $M_{2}$ & $S_{2}$ & $K_{1}$ & $O_{1}$ \\
\hline 1 & $(-16 \pm 29,54 \pm 32)$ & $(0 \pm 2,-4 \pm 3)$ & $(44 \pm 16,17 \pm 15)$ & $(8 \pm 8,5 \pm 11)$ \\
2 & $(-2 \pm 1,-3 \pm 1)$ & $(0 \pm 1,0 \pm 0)$ & $(14 \pm 7,3 \pm 1)$ & $(1 \pm 2,1 \pm 1)$ \\
3 & $(5 \pm 6,-22 \pm 11)$ & $(1 \pm 2,0 \pm 3)$ & $(2 \pm 2,-2 \pm 3)$ & $(0 \pm 1,0 \pm 2)$ \\
4 & $(1 \pm 2,-8 \pm 3)$ & $(0 \pm 1,0 \pm 1)$ & $(3 \pm 3,-5 \pm 6)$ & $(0 \pm 1,-1 \pm 1)$ \\
5 & $(2 \pm 3,13 \pm 7)$ & $(-1 \pm 1,1 \pm 1)$ & $(11 \pm 5,8 \pm 6)$ & $(2 \pm 1,2 \pm 2)$ \\
\hline
\end{tabular}

energetic southern flanks of the YP. It is therefore crucial to utilize the model data to account for the energetic parts of the plateau. In the following we shall rely on the model results to discuss the energetics in the region and its role for vertical mixing.

The baroclinic radiation and depth-integrated dissipation rates are obtained from the model. A negative radiation is horizontal convergence of the depth-integrated flux and indicates that the location is a sink, whereas a positive radiation indicates that the site is a source for baroclinic energy. Volume-integrated conversion, radiation, and dissipation rates are calculated over the YP region bounded between $5^{\circ} \mathrm{W}$ and $25^{\circ} \mathrm{E}$ zonally, 79 and $83^{\circ} 30^{\prime} \mathrm{N}$ meridionally, and by the $250 \mathrm{~m}$ isobath north of Svalbard. Surface area in this domain with water depth deeper than $250 \mathrm{~m}$ is approximately $2 \times 10^{11} \mathrm{~m}^{2}$, with a mean water depth of $2300 \mathrm{~m}$. For the $M_{2}$ constituent, several outliers in the radiation data (in total 10 grid points, all between the 750 and $2250 \mathrm{~m}$ isobaths with radiation values between 0.03 and $0.06 \mathrm{~W} \mathrm{~m}^{-2}$ ) are co-located with weak conversion rates of an order of $10^{-3} \mathrm{~W} \mathrm{~m}^{-2}$, leading to unphysical negative dissipation rates. We removed these points from the calculations. The volume-integrated conversion rate in the region is $322 \mathrm{MW}$ for $M_{2}$ and $618 \mathrm{MW}$ for $K_{1}$; the radiation is 8 and $1 \mathrm{MW}$, respectively. This indicates that despite substantial energy conversion into internal tides, only a minute fraction (if any) propagates out of the region, implying substantial local dissipation. The spatial distribution of depth-integrated dissipation rate for the $M_{2}$ and $K_{1}$ components is shown in Fig. 7. Total dissipation integrated over the domain is 314 and $617 \mathrm{MW}$ for the $M_{2}$ and $K_{1}$ constituents, respectively.

The conversion is spatially variable, and is particularly concentrated near the $2000 \mathrm{~m}$ isobath in the northern flanks of the plateau (Fig. 6). Dissipation is typically elevated where the conversion rates are large and the spatial distribution is characterized by several regions (hot spots) where the dissipation is enhanced (Fig. 7). For quantification of their contribution, we define hot spots as grid-volumeintegrated total dissipation exceeding $0.5 \mathrm{MW}$ (corresponding to approximately $10^{-2} \mathrm{~W} \mathrm{~m}^{-2}$ depth-integrated dissipation, strong colours in Fig. 7). The percent of area with hot spots is $7 \%$ for $M_{2}, 11 \%$ for $K_{1}$, and $15 \%$ for the sum of $M_{2}$ and $K_{1}$. Dissipation of diurnal energy is concentrated on the northern flanks of the plateau, around the CEAREX-O drift site, over the shallow part of the plateau near the MIZEX83 drift, and around $17-18^{\circ}$ E north of Svalbard. Dissipation of semidiurnal energy shows a similar pattern, but with relatively less pronounced dissipation near the CEAREX-O drift site. There is a patch of elevated dissipation near station 4 where the highest mixing rates were recorded during our cruise (Fig. 4). These locations of energetic turbulence also coincide with regions of large barotropic tide velocities. The maximum tidal velocity amplitudes during one spring-neap cycle exceed $0.4 \mathrm{~m} \mathrm{~s}^{-1}$ in localized regions over the plateau and approach $1 \mathrm{~m} \mathrm{~s}^{-1}$ over the shelf north of Svalbard east of our station 4 . Over the plateau, the largest tidal velocity is near the seamount where D'Asaro and Morison (1992) inferred eddy diffusivities greater than $10^{-4} \mathrm{~m}^{2} \mathrm{~s}^{-1}$ from XCP shear. Close to the CEAREX-O camp, on the northern flanks, the maximum tidal velocity is approximately $25 \mathrm{~cm} \mathrm{~s}^{-1}$, greater than that at our stations.

The spatial variability is further investigated using the integrated conversion and radiation rates over volumes bounded by increasing isobaths, following Kang and Fringer (2012). The results for the $M_{2}$ and $K_{1}$ constituents are shown in Fig. 8 using $250 \mathrm{~m}$ depth bins. Cumulative rates between chosen isobaths are tabulated in Table 5. The barotropic tide is converted to internal tide at all depths, for both constituents. The semidiurnal conversion shows an increase at isobaths deeper than $1500 \mathrm{~m}$ (over the sloping sides of the plateau) and with a peak around the $3000 \mathrm{~m}$ isobath (Fig. 8a). The radiation is nil below the $750 \mathrm{~m}$ isobath, positive between 750 and $2000 \mathrm{~m}$, and negative for deeper water. All of the semidiurnal energy converted at depths shallower than $750 \mathrm{~m}$, and also the amount generated in deeper water which propagates into shallower depth, are thus dissipated over the shelves. The slope between 750 and $2000 \mathrm{~m}$ depth is a generation site for propagating internal tide (positive radiation). The deeper part of the slope is a sink, and dissipates the energy that is locally generated as well as the fraction that is radiated from the upper slope. The radiation for these trapped waves must be interpreted in the context of a decay of energy with an $e$-folding scale of Rossby radius (Sect. 6). 

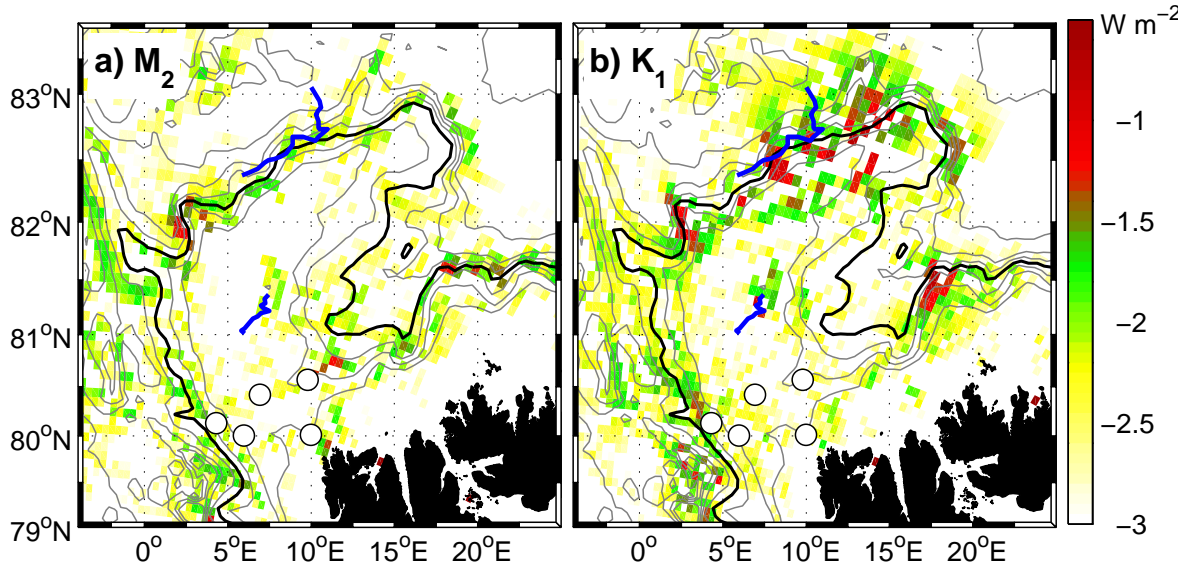

Figure 7. Depth-integrated dissipation rate, presented in base-10 logarithm, for the (a) $M_{2}$ and (b) $K_{1}$ constituents obtained from STORMTIDE. Isobaths (grey) drawn at $500 \mathrm{~m}$ intervals are from the model topography. The $2000 \mathrm{~m}$ isobath is drawn in black for reference. Station positions (open circles) and the drift of CEAREX-O (Padman and Dillon, 1991) and MIZEX83 (D'Asaro and Morison, 1992) are also shown.

Table 5. Volume-integrated conversion and radiation rates for the $M_{2}$ and $K_{1}$ constituents, bounded by selected isobaths. Shallower than $250 \mathrm{~m}$ (not listed), there is approximately $10 \mathrm{MW}$ conversion, for both $M_{2}$ and $K_{1}$, balanced by local dissipation.

\begin{tabular}{crrrrrr}
\hline $\begin{array}{c}M_{2} \\
\text { Isobath } \\
(\mathrm{m})\end{array}$ & $\begin{array}{r}\text { Conversion } \\
(\mathrm{MW})\end{array}$ & $\begin{array}{r}M_{2} \\
\text { Radiation } \\
(\mathrm{MW})\end{array}$ & $\begin{array}{r}M_{2} \\
\text { Dissipation } \\
(\mathrm{MW})\end{array}$ & $\begin{array}{r}K_{1} \\
\text { Conversion } \\
(\mathrm{MW})\end{array}$ & $\begin{array}{r}K_{1} \\
\text { Radiation } \\
(\mathrm{MW})\end{array}$ & $\begin{array}{r}K_{1} \\
\text { Dissipation } \\
(\mathrm{MW})\end{array}$ \\
\hline $250-750$ & 19 & 0 & 19 & 42 & -4 & 46 \\
$750-2000$ & 85 & 80 & 5 & 175 & -23 & 198 \\
$2000-5000$ & 218 & -72 & 290 & 401 & 28 & 373 \\
\hline
\end{tabular}

Volume-integrated conversion of $K_{1}(618 \mathrm{MW})$ is approximately twice that of $M_{2}$. Similar to the $M_{2}$ pattern, there is radiation away from the upper part of the slope, whereas the deeper slope is a sink for the baroclinic $K_{1}$ energy flux. The major source and sink regions are relatively more constrained by the isobaths for $K_{1}(1000-1500$ and 1750 $2250 \mathrm{~m}$ ) compared to a broader distributed $M_{2}$ (750-2000 and $2250-4000 \mathrm{~m}$ ). Most of the dissipation occurs deeper than $1500 \mathrm{~m}$. The dissipation curve shows an approximate local conversion-dissipation balance over the shallows and also on the deeper part of the slope, but the dissipation exceeds twice the conversion rates between 1500 and $2000 \mathrm{~m}$ depth; all the $K_{1}$ energy radiation from the upper slope is dissipated here.

\section{Discussion}

The model results show substantial barotropic tidal fluxes around the YP and localized regions of large barotropic-tobaroclinic energy conversion rates for both $K_{1}$ and $M_{2}$ constituents. These conversion sites are shown to be associated with baroclinic energy fluxes. Is it realistic to have baroclinic energy fluxes and radiation for tides above their corresponding critical latitudes? Analogous to barotropic con- tinental shelf waves, variable bottom topography of ridges, seamounts and plateaus in homogeneous water can support trapped waves (Rhines, 1969; Huthnance, 1974). If, for example, diurnal tidal frequency is close to the natural frequency of one of such free wave modes, the topographically trapped free wave will be resonantly excited by the oscillation of the diurnal tide. Using arbitrary stratification, Brink (1989) showed that sub-inertial baroclinic trapped waves are also supported at isolated seamounts. Wang and Mooers (1976) showed that in a continuously stratified ocean with sloping bottom, topographic Rossby waves are the only form of sub-inertial wave motion (for a negligible coastal wall), and reduce to barotropic shelf waves and to bottom-trapped waves in the limits of small and large stratification, respectively. The energy of the topographically trapped waves propagates along the slope, around the topographic feature with a decay scale of Rossby radius of deformation and negligible radiation in the cross-slope direction. Sub-inertial internal wave energy and energy fluxes have been observed and modelled elsewhere (Allen and Thomson, 1993; Tanaka et al., 2010; Johnston and Rudnick, 2014; Robertson, 2001; Kunze and Toole, 1997). The internal Rossby radius, $c_{1} / f$, for the first mode eigenspeed obtained from the modal analysis of our observational data, varies between 3 and $5 \mathrm{~km}$. 

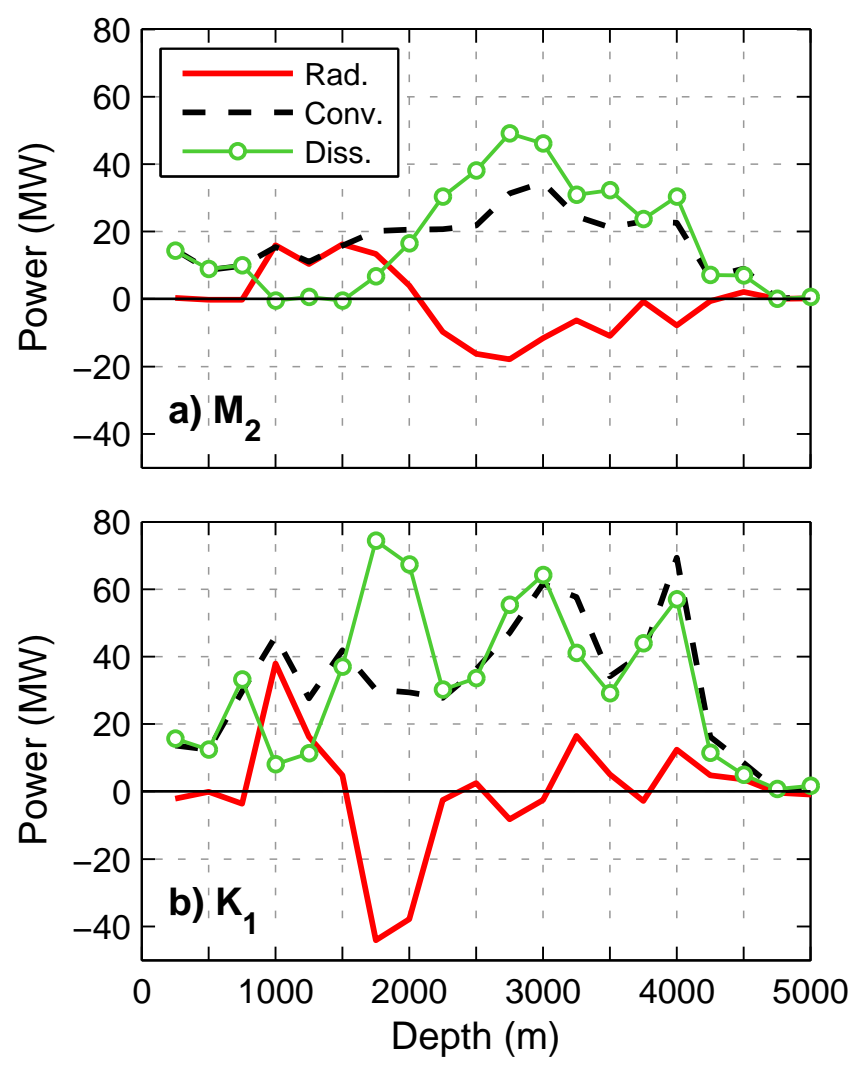

Figure 8. Total baroclinic radiation (red), conversion (dashed black), and dissipation (green, circles) for the (a) $M_{2}$ and (b) $K_{1}$ constituents, integrated in $250 \mathrm{~m}$ isobath bounded volumes.

The bottom slope between the 1000 and $2000 \mathrm{~m}$ isobaths along the northwestern slope, representative of the generation sites, is $0.06( \pm 0.03)$. The cross-slope distance covered between the 1000 and $2000 \mathrm{~m}$ isobaths is thus $17 \mathrm{~km}( \pm 8)$. If the trapped wave generated between these isobaths decays with the Rossby radius, a decay to $5 \%$ of the background value occurs between 9 and $15 \mathrm{~km}$. Hence, the substantial inferred radiation near the isobaths where conversion occurs (Fig. 8) is plausible.

The bottom-trapped tides in the Arctic Ocean are of particular importance because most of the Arctic Basin is located north of critical latitude of the most energetic tidal constituent $M_{2}$ (Falahat and Nycander, 2014). Using global numerical models, baroclinic tidal energy (including poleward of the critical latitudes) are reported by Niwa and Hibiya (2011) for the major diurnal constituents and by Müller (2013) for the major diurnal and semidiurnal constituents. In an idealized study, Falahat and Nycander (2014) examine the bottom-trapped internal tides for the $M_{2}, K_{1}$, and $O_{1}$ tidal constituents over the global ocean. To infer the energy conversion rates from the barotropic tides to bottom-trapped internal tides, they calculate the energy density for linear inviscid waves and assume that the trapped wave energy, for all vertical modes, decays over a 3-day timescale. This ad hoc timescale is representative of Fieberling Seamount which is a strongly forced and damped system with large dissipation and eddy diffusivity (Kunze and Toole, 1997). In the Arctic Ocean, Falahat and Nycander (2014) inferred an areaintegrated energy flux of $1.1 \mathrm{GW}$ for topography-trapped internal tides (sum of the $M_{2}, K_{1}$, and $O_{1}$ constituents, where about $70 \%$ is due to $M_{2}$ ). The diurnal component, of about $0.3 \mathrm{GW}$, is 1 order of magnitude less than the diurnal internal tides in the Arctic Ocean reported in Müller (2013), and hence should be considered as a lower bound.

At high latitudes, diurnal tides with frequencies close to the half of the inertial frequency are a likely source to force resonant-trapped waves (Huthnance, 1974). In the Rockall Bank, the diurnal tidal frequencies are close to the resonance frequency of a natural trapped mode progressing clockwise around the bank, leading to strongly excited diurnal currents consistent with observations (Huthnance, 1974). A similar excitation of diurnal currents was also shown around the Bear Island near the $M_{2}$ critical latitude (Huthnance, 1981). Yermak Plateau is an area known to have resonantly enhanced diurnal tides, particularly over the northern flanks (Hunkins, 1986; Chapman, 1989; Padman et al., 1992). Using a barotropic model with an idealized axisymmetric submarine plateau both Hunkins (1986) and Chapman (1989) showed near-resonant diurnal trapped topographic waves propagating around the YP. While Hunkins (1986) looked at the free waves in a frictionless ocean, Chapman (1989) included friction and forcing by rectilinear $K_{1}$ tidal currents (i.e. forced and damped trapped waves). The topography of the YP, however, is not axisymmetric (Fig. 1). Padman et al. (1992) showed that dispersion relations derived separately on the northwestern and eastern flanks of the Plateau suggest free diurnal waves on the northwest slope (near the CEAREXO site) but approximately zero group velocity on the eastern slope. This is inconsistent with the axisymmetric model and with a resonant interaction mechanism related to the path length of a free wave that encircles the entire plateau. They proposed an alternative generation where diurnal energy is due to topographic diurnal waves on the eastern part where the group velocity is near zero, allowing maximum amplification. Although these studies address the barotropic diurnal currents in neutral stratification (for simplicity), they are applicable to baroclinic solutions (Brink, 1989; Wang and Mooers, 1976). For example, Tanaka et al. (2010) uses the baroclinic coastal trapped wave solutions to explain the subinertial diurnal baroclinic tidal energy propagating around the Kuril Islands. On the continental slope of the Laptev Sea, Pnyushkov and Polyakov (2012) reported that the baroclinic solutions of the topographically trapped waves show no significant change of the cross-slope structure of tidal current and sea level amplitudes compared with the barotropic experiment.

Sub-inertial internal wave energy and energy fluxes have been observed and modelled elsewhere. Over the Juan de Fuca Ridge, trapped (laterally and vertically) baroclinic 
subinertial motions were reported (Allen and Thomson, 1993). In a numerical study, Tanaka et al. (2010) show that most of the internal wave energy subtracted from the diurnal barotropic tide is dissipated within the Kuril straits. $K_{1}$ tidal frequency is sub-inertial in this area and the tidal energy is fed into topographically trapped waves which propagate along slope around each island with negligible radiation away from the straits. Energy subtracted from the $K_{1}$ barotropic tide is approximately $30 \mathrm{GW}$; most of the energy dissipates locally, only $0.6 \mathrm{GW}$ radiating out from the analysed domain. The local conversion and dissipation balance is similar to what we found near the YP. Johnston and Rudnick (2014) observed topographically trapped diurnal internal waves along the California continental slope and over the Santa Rosa-Cortes Ridge in the southern California Bight. The diurnal (sub-inertial) internal tides are more energetic than the semidiurnal internal tides and are associated with elevated diffusivities near topography. Using current measurements in the upper $200 \mathrm{~m}$ in about $2700 \mathrm{~m}$ deep water on the continental slope of the Laptev Sea, Pnyushkov and Polyakov (2012) inferred baroclinic tide in the upper $50 \mathrm{~m}$, twice as energetic as the barotropic tidal currents. Numerical solutions of trapped waves over the continental shelf and slope suggest resonance and enhancement of semidiurnal energy consistent with the observations. Poleward of the critical latitudes, near-inertial internal waves have also been observed. For a review of the near-inertial internal tides in the Weddell Sea in Antarctica see Robertson (2001). Over Fieberling Seamount near $32^{\circ} \mathrm{N}$ Kunze and Toole (1997) reported vortex-trapped near-inertial diurnal internal waves. The dissipation rates are strong enough to dissipate the $K_{1}$ motions within 3 days, implying a strongly forced and damped environment. At the YP, $M_{2}$ is the strongest semidiurnal component. D'Asaro and Morison (1992) reported that tides here are an attractive source for enhanced near-inertial band energy where sub-inertial $M_{2}$ tide generated on the seamount is trapped to the seamount by the barotropic vorticity field.

At the YP region, the trapped diurnal tides are likely generated by resonant forcing of diurnal tides through the processes described in Chapman (1989) and Padman et al. (1992). The trapped semidiurnal tides are possibly generated locally. Internal waves are generated over critical slopes where the ratio $\gamma=\beta / \alpha$ is unity. Here $\beta$ is the topographic slope and $\alpha=\left(\omega^{2}-f^{2}\right)^{1 / 2}\left(N^{2}-\omega^{2}\right)^{-1 / 2}$ is the characteristic along which linear internal waves with frequency $\omega$ propagate (i.e. the horizontal slope of the internal wave ray). Although the critical condition $(\gamma=1)$ is optimal, internal wave generation at supercritical slopes $(\gamma>1)$ is also common. The critical condition also leads to enhanced shear and turbulence (Eriksen, 1985). As the turning latitude where $\omega=f$ is approached; however, the non-linear terms become increasingly important and the parameter $\gamma$ becomes a crude indicator of the potential for internal wave generation (Vlasenko et al., 2003). Poleward of the turning latitude negative background vorticities can effectively reduce

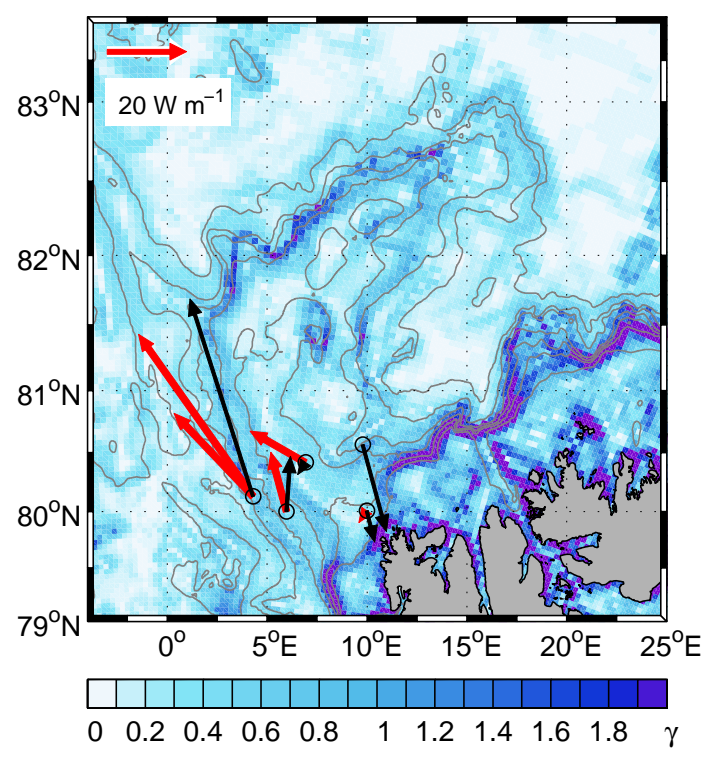

Figure 9. Contours of $\gamma$, the ratio of semidiurnal internal wave characteristic to the bottom slope. An effective inertial frequency of $0.95 f$ (i.e. assuming negative, anti-cyclonic, relative vorticity of $0.05 f)$ is used in the calculations. Superimposed are the isobaths $(250,500,750,1000,1500,2000$, and $3000 \mathrm{~m})$, station positions (circles), and the depth-integrated baroclinic semidiurnal energy flux (arrows) with scale given on the top left. Red arrows are inferred from the observations, whereas the black arrows are from STORMTIDE (sum of $M_{2}$ and $S_{2}$ ) averaged over $10 \mathrm{~km}$ range of the stations. At station 1 the two observed flux vectors are obtained from the VM-ADCP and the XCP data.

the inertial frequency and thereby potentially allow for linear sub-inertial internal waves (Kunze and Toole, 1997). We evaluate $\gamma$ for the $M_{2}$ frequency, using an effective inertial frequency of $0.95 f$, and the buoyancy frequency from the survey mean full-depth CTD profiles. Anti-cyclonic loops and negative background vorticity on the order of $10^{-5} \mathrm{~s}^{-1}$ were previously inferred from floats over YP (Gascard et al., 1995). For the $M_{2}$ constituent, the northwestern flanks and the seamount region on the plateau are characterized by values of $\gamma$ between 0.8 and 1.2 (Fig. 9), which favour the generation of semidiurnal internal tides and suggest elevated shear and mixing, consistent with earlier observations. The amplitude of depth-integrated baroclinic semidiurnal energy flux is about $15-50 \mathrm{~W} \mathrm{~m}^{-1}$ at station 1 , and can be compared to the values from STORMTIDE (Fig. 9). The sampling is limited, however, Fig. 9 shows depth-integrated semidiurnal baroclinic energy flux on the southern YP where $\gamma$ is near unity. The large STORMTIDE baroclinic semidiurnal fluxes apparent on the flanks of the YP and along the slope north of Svalbard (Fig. 6a) are also co-located with near-critical slopes. An entirely different generation mechanism is possible when non-linearity is strong, leading to unsteady lee waves at relatively short horizontal length scales (see, e.g., Vlasenko et al., 2003). The STORMTIDE results, however, 
do not include the effect of such non-linear internal wave generation.

A crude estimate of the total energy dissipated over the YP can be made from observations as follows. We use the same domain surface area of $2 \times 10^{11} \mathrm{~m}^{2}$ and the mean water depth of $2300 \mathrm{~m}$ inferred from the model. We choose two representative $\varepsilon$ profiles: a lower bound $\left(\varepsilon_{2300 \mathrm{~m}-\mathrm{min}}\right)$ and an upper bound ( $\varepsilon_{2300 \mathrm{~m} \text {-max }}$ ), each constructed to $2300 \mathrm{~m}$ depth. For the lower and upper bounds, we extend the $\varepsilon_{\min }$ and $\varepsilon_{\max }$ profile, respectively, of stations 1 and 2 to $2300 \mathrm{~m}$ depth. Station 2, comparably to station 3 , is representative of the typical upper level of dissipation rates over the YP, excluding localized, enhanced dissipation observed on the northwestern flanks and the seamount over the plateau. At such locations where the bottom topography is near critical to the semidiurnal waves (Fig. 9), the dissipation profile of station 4 would be more appropriate. Using $\varepsilon_{2300 \mathrm{~m} \text {-min }}$ and $\varepsilon_{2300 \mathrm{~m} \text {-max }}$, the lower and upper bounds on the total energy dissipated are 100 and $800 \mathrm{MW}$, respectively. Assuming 10-15\% of the region is characterized by exceptionally enhanced dissipation rates (hot spots, Sect. 5), using $2300 \mathrm{~m}$ integrated dissipation from station 4, 400-600 MW can be attributed to localized mixing regions. The bounds on the dissipation rate, including the hot spots, are thus approximately 500 and $1100 \mathrm{MW}$. This observation-based estimate of the total dissipation includes a contribution from dissipation of internal tides (of diurnal and semidiurnal period) as well as other contributions such as turbulence due to mean shear.

The domain-integrated dissipation from STORMTIDE is $931 \mathrm{MW}$ (sum of $K_{1}$ and $M_{2}$, where $M_{2}$ is $314 \mathrm{MW}$ ), in the range inferred from the observations, and suggests that almost the entire dissipation (below $50 \mathrm{~m}$ depth) can be explained by the dissipation of baroclinic tidal energy. Using a global domain numerical model with 10 vertical layers, Simmons et al. (2004) reported approximately $1 \mathrm{GW}$ of $M_{2}$ conversion rate in the Fram Strait-Yermak Plateau region. Their box for the calculation of this domain covers $76-90^{\circ} \mathrm{N}$ between $20^{\circ} \mathrm{W}$ and $15^{\circ} \mathrm{E}$. For the same domain, we obtain $0.62 \mathrm{GW}$ for $M_{2}$ and $0.63 \mathrm{GW}$ of $K_{1}$ from STORMTIDE. According to our model result in the Fram Strait-Yermak Plateau region, about $50 \%$ of the $M_{2}$ conversion, and almost $100 \%$ of the $K_{1}$ conversion occurs over the YP. Our calculations suggest that $40-80 \%$ of the energy contained in the internal tides in this extended region is dissipated around the YP.

The volume-integrated total dissipation can be converted to an eddy diffusivity using the Osborn model (Osborn, 1980), which can then be related to turbulent vertical heat flux using the mean vertical temperature gradient. We extracted annual average temperature and salinity profiles from the Polar Science Centre Hydrographic Climatology (Steele et al., 2001), from 125 grid points in the domain used in the YP energetics calculations. Domain-averaged annual mean temperature profile below $100 \mathrm{~m}$ increases with depth at a rate of $1^{\circ} \mathrm{C}$ per $100 \mathrm{~m}$ down to the core of the Atlantic layer at $250 \mathrm{~m}$ depth below which the temperature decreases. If the entire dissipation takes place in this $150 \mathrm{~m}$ thick layer between 100 and $250 \mathrm{~m}$ (average $N^{2}=1.5 \times 10^{-5} \mathrm{~s}^{-2}$ ), the average upward turbulent heat flux is obtained as $17 \mathrm{~W} \mathrm{~m}^{-2}$. This value is comparable to the average ocean-to-ice heat flux of $22 \mathrm{~W} \mathrm{~m}^{-2}$ measured by McPhee et al. (2003) in the YP region. The dissipation of baroclinic tidal energy is thus a significant contributor to turbulent mixing and cooling of the Atlantic layer north of Svalbard.

\section{Conclusions}

Observations made in summer 2007 over the southern part of the Yermak Plateau (YP), together with results from a global high-resolution ocean circulation and tide model simulation (STORMTIDE) are used to investigate the role of tides, topography, and trapped internal tides in turbulent mixing near the YP. The plateau located northwest of Svalbard is of interest because it is the main topographic obstacle for the Atlantic Water carried by the West Spitsbergen Current to the Arctic. Tidal forcing, barotropic-to-baroclinic energy conversion rates, baroclinic energy fluxes, and dissipation rates in the region are discussed. Observational-based analysis suffers from errors as a result of short sampling duration, vertically imperfect sampling, and sloping topography. The STORMTIDE model results are limited to interpretation for linear wave characteristics.

Depth-integrated conversion rates, baroclinic energy fluxes, and dissipation rates show large spatial variability over the YP. The energetics are dominated by the $K_{1}$ and $M_{2}$ constituents. The volume-integrated conversion rate over the region enclosing the topographic feature is $322 \mathrm{MW}$ for $M_{2}$ and $618 \mathrm{MW}$ for $K_{1}$. This corresponds to about $50 \%$ of the $M_{2}$ and approximately all of the $K_{1}$ conversion in a larger domain covering the entire Fram Strait, extended to the North Pole $\left(76-90^{\circ} \mathrm{N}, 20^{\circ} \mathrm{W}-15^{\circ} \mathrm{E}\right)$. Despite the large energy conversion, internal tides are trapped with a negligible radiation out of the YP region, implying substantial local dissipation. The suggested enhanced levels of dissipation are supported by past observations showing high dissipation rates and strong mixing over the upper slope on the northern flanks (Hunkins, 1986; Padman and Dillon, 1991) and in the vicinity of a seamount over the plateau (D'Asaro and Morison, 1992). At the YP region, the trapped diurnal tides are likely generated by resonant forcing of diurnal tides through the processes described in Chapman (1989) and Padman et al. (1992). The trapped semidiurnal tides are possibly generated locally over near critical slopes. When a plausible negative background relative vorticity is allowed, we find the bottom topography in these regions critical to the semidiurnal frequency. Similar bottom slopes are also typical over the shelf north of Svalbard, close to one of our station with the largest mixing rates. 
An approximate local conversion-dissipation balance is inferred over regions shallower than $1000 \mathrm{~m}$, and also in the deep part of the sloping flanks, deeper than about $2000 \mathrm{~m}$. On average, there is radiation of the baroclinic $K_{1}$ and $M_{2}$ energy away from the upper part of the slope, which is dissipated over the deeper isobaths. Most of the dissipation occurs in water deeper than $1500 \mathrm{~m}$. Approximately the entire $K_{1}$ energy radiated in the region is dissipated between 1000 and $1500 \mathrm{~m}$ depth. The dissipation of the radiated $M_{2}$ energy is broadly distributed over the $2250-4000 \mathrm{~m}$ isobaths.

From observations, we inferred lower and upper bounds on the total dissipation rate of 500 and $1100 \mathrm{MW}$, of which approximately 400-600 MW can be attributed to the contribution of hot spots. The domain-integrated dissipation from STORMTIDE is in the range inferred from the observations, and suggests that almost all the dissipation in the region can be attributed to the dissipation of baroclinic tidal energy. Using the climatological temperature profiles and stratification averaged above the core of the Atlantic layer, the volumeintegrated total dissipation leads to an average upward turbulent heat flux that is comparable to the average ocean-to-ice heat flux measured in the YP region. Although our regional calculations are crude, they underscore that the dissipation of baroclinic tidal energy can be a significant contributor to turbulent mixing and cooling of the Atlantic layer north of Svalbard. The role of tidal forcing in the heat budget of the Arctic Ocean in general merits further studies.

Acknowledgements. This study is funded by the Research Council of Norway through project nos. 178641/S30 and 229786/E10. Authors thank the crew and the participants of the cruise for their efforts during the field work. Helpful comments provided by two anonymous reviewers and the topic editor John M. Huthnance are appreciated.

Edited by: J. M. Huthnance

\section{References}

Alford, M. H., Cronin, M. F., and Klymak, J. M.: Annual cycle and depth penetration of wind-generated near-inertial internal waves at Ocean Station Papa in the northeast Pacific, J. Phys. Oceanogr., 42, 889-909, 2012.

Allen, S. E. and Thomson, R. E.: Bottom-trapped subinertial motions over midocean ridges in a stratified rotating fluid, J. Phys. Oceanogr., 23, 566-581, 1993.

Amante, C. and Eakins, B.: ETOPO1 1 Arc-Minute Global Relief Model: Procedures, Data Sources and Analysis. NOAA Technical Memorandum NESDIS NGDC-24. National Geophysical Data Center, NOAA, 2009.

Brink, K. H.: The effect of stratification on seamount-trapped waves, Deep-Sea Res. A., 36, 825-844, 1989.

Chapman, D. C.: Enhanced subinertial diurnal tides over isolated topographic features, Deep-Sea Res., 36, 815-824, 1989.
Chen, C., Gao, G., Qi, J., Proshutinsky, A., Beardsley, R. C.and Kowalik, Z., Lin, H., and Cowles, G.: A new highresolution unstructured-grid finite-volume Arctic Ocean model (AO-FVCOM): an application for tidal studies, J. Geophys. Res., 114, C08017, doi:10.1029/2008JC004941, 2009.

D'Asaro, E. A. and Morison, J. H.: Internal waves and mixing in the Arctic Ocean, Deep-Sea Res., 39, S459-S484, 1992.

Egbert, G. D. and Ray, R. D.: Significant dissipation of tidal energy in the deep ocean inferred from satellite altimeter data, Nature, 405, 775-778, 2000.

Eriksen, C. C.: Implications of ocean bottom reflection for internal wave spectra and mixing, J. Phys. Oceanogr., 15, 1145-1156, 1985.

Falahat, S. and Nycander, J.: On the generation of bottomtrapped internal tides, J. Phys. Oceanogr., 45, 526-545, doi:10.1175/JPO-D-14-0081.1, 2014.

Fer, I.: Scaling turbulent dissipation in an Arctic fjord, Deep-Sea Res. II, 53, 77-95, 2006.

Fer, I. and Sundfjord, A.: Observations of upper ocean boundary layer dynamics in the marginal ice zone, J. Geophys. Res., 112, C04012, doi:10.1029/2005JC003428, 2007.

Fer, I., Skogseth, R., and Geyer, F.: Internal waves and mixing in the Marginal Ice Zone near the Yermak Plateau, J. Phys. Oceanogr., 40, 1613-1630, 2010.

Foreman, M. G. G., Cherniawsky, J. Y., and Ballantyne, V. A.: Versatile harmonic tidal analysis: improvements and applications, J. Atmos. Ocean. Technol., 26, 806-817, doi:10.1175/2008jtecho615.1, 2009.

Garrett, C. and Kunze, E.: Internal tide generation in the deep ocean, Annu. Rev. Fluid Mech., 39, 57-87, 2007.

Gascard, J. C., Richez, C., and Roaualt, C.: New insights on largescale oceanography in Fram Strait: the West Spitsbergen Current, in: Arctic oceanography, marginal ice zones and continental shelves, edited by: Smith Jr., W. O. and Grebmeier, J., vol. 49, chap. 5, 131-182, AGU, Washington D.C., USA, 1995.

Hunkins, K.: Anomalous diurnal tidal currents on the Yermak Plateau, J. Mar. Res., 44, 51-69, 1986.

Huthnance, J. M.: On the diurnal tidal currents over Rockall Bank, Deep-Sea Res., 21, 23-35, 1974.

Huthnance, J. M.: Large tidal currents near Bear Island and related tidal energy losses from the North Atlantic, Deep-Sea Res., 28A, 51-70, 1981.

Johnston, T. M. S. and Rudnick, D. L.: Trapped diurnal internal tides, propagating semidiurnal internal tides, and mixing estimates in the California Current System from sustained glider observations, 2006-2012, Deep-Sea Res. II, 112, 61-78, doi:10.1016/j.dsr2.2014.03.009, 2014.

Jungclaus, J. H., Keenlyside, N., Botzet, M., Haak, H., Luo, J. J., Latif, M., Marotzke, J., Mikolajewicz, U., and Roeckner, E.: Ocean circulation and tropical variability in the coupled model ECHAM5/MPI-OM, J. Clim., 19, 3952-3972, doi:10.1175/JCLI3827.1, 2006.

Kagan, B. A. and Sofina, E. V.: Surface and internal semidiurnal tides and tidally induced diapycnal diffusion in the Barents Sea: a numerical study, Cont. Shelf Res., 91, 158-170, doi:10.1016/j.csr.2014.09.010, 2014.

Kang, D. J. and Fringer, O.: Energetics of barotropic and baroclinic tides in the Monterey Bay area, J. Phys. Oceanogr., 42, 272-290, 2012. 
Kelly, S. M., Nash, J. D., and Kunze, E.: Internal-tide energy over topography, J. Geophys. Res., 115, C06014, doi:10.1029/2009JC005618, 2010.

Klymak, J. M., Pinkel, R., and Rainville, L.: Direct breaking of the internal tide near topography: Kaena ridge, Hawaii, J. Phys. Oceanogr., 38, 380-399, 2008.

Kunze, E. and Toole, J. M.: Tidally driven vorticity, diurnal shear, and turbulence atop Fieberling Seamount, J. Phys. Oceanogr., 27, 2663-2693, 1997.

Kunze, E., Rosenfeld, L. K., Carter, G. S., and Gregg, M. C.: Internal waves in Monterey Submarine Canyon, J. Phys. Oceanogr., 32, 1890-1913, 2002.

Leaman, K. D. and Sanford, T. B.: Vertical energy propagation of inertial waves: A vector spectral analysis of velocity profiles, J. Geophys. Res., 80, 1975-1978, 1975.

McPhee, M. G., Kikuchi, T., Morison, J. H., and Stanton, T. P.: Ocean-to-ice heat flux at the North Pole environmental observatory, Geophys. Res. Lett., 30, 2274, doi:10.1029/2003GL018580, 2003.

Müller, M.: On the space- and time-dependence of barotropic-tobaroclinic tidal energy conversion, Ocean Model., 72, 242-252, doi:10.1016/j.ocemod.2013.09.007, 2013.

Müller, M., Cherniawsky, J. Y., Foreman, M. G. G., and von Storch, J. S.: Global $\mathrm{M}_{2}$ internal tide and its seasonal variability from high resolution ocean circulation and tide modeling, Geophys. Res. Lett., 39, L19607, doi:10.1029/2012g1053320, 2012.

Müller, M., Cherniawsky, J., Foreman, M. G., and von Storch, J.S.: Seasonal variation of the $\mathrm{M}_{2}$ tide, Ocean Dyn., 64, 159-177, doi:10.1007/s10236-013-0679-0, 2014.

Nash, J. D., Alford, M. H., and Kunze, E.: Estimating internal wave energy fluxes in the ocean, J. Atmos. Ocean. Technol., 22, 15511570, 2005.

Nash, J. D., Kunze, E., Lee, C. M., and Sanford, T. B.: Structure of the baroclinic tide generated at Kaena Ridge, Hawaii, J. Phys. Oceanogr., 36, 1123-1135, 2006.

Niwa, Y. and Hibiya, T.: Estimation of baroclinic tide energy available for deep ocean mixing based on three-dimensional global numerical simulations, J. Oceanogr., 67, 493-502, 2011.

Nycander, J.: Generation of internal waves in the deep ocean by tides, J. Geophys. Res., 110, C10028, doi:10.1029/2004jc002487, 2005.

Osborn, T. R.: Estimates of the local rate of vertical diffusion from dissipation measurements, J. Phys. Oceanogr., 10, 83-89, 1980.

Padman, L. and Dillon, T.: Turbulent mixing near the Yermak Plateau during the coordinated Eastern Arctic Experiment, J. Geophys. Res., 96, 4769-4782, 1991.

Padman, L., Plueddemann, A. J., Muench, R. D., and Pinkel, R.: Diurnal tides near the Yermak Plateau, J. Geophys. Res., 97, 12639-12652, 1992.

Phillips, O. M.: The Dynamics of the Upper Ocean, 2nd edn., Cambridge University Press, Cambridge, UK, 1977.

Plueddemann, A. J.: Internal wave observations from the Arctic Environmental Drifting Buoy, J. Geophys. Res., 97, 12619-12638, 1992.
Pnyushkov, A. V. and Polyakov, I. V.: Observations of tidally induced currents over the continental slope of the Laptev Sea, Arctic Ocean, J. Phys. Oceanogr., 42, 78-94, doi:10.1175/JPO-D11-064.1, 2012.

Rhines, P. B.: Slow oscillations in an ocean of varying depth, 2: Islands and seamounts, J. Fluid Mech., 37, 191-205, 1969.

Robertson, R.: Internal tides and baroclinicity in the southern Weddell Sea 1. Model description, J. Geophys. Res., 106, 2700127016, 2001.

Simmons, H., Chang, M.-H., Chang, Y.-T., Chao, S.-Y., Fringer, O., Jackson, C., and Ko., D.: Modeling and prediction of internal waves in the South China Sea, Oceanography, 24, 88-99, doi:10.5670/oceanog.2011, 2011.

Simmons, H. L., Hallberg, R. W., and Arbic, B. K.: Internal wave generation in a global baroclinic tide model, Deep-Sea Res. II, 51, 3043-3068, 2004.

Sirevaag, A. and Fer, I.: Early spring oceanic heat fluxes and mixing observed from drift stations north of Svalbard, J. Phys. Oceanogr., 39, 3049-3069, 2009.

Stammer, D., Ray, R. D., Andersen, O. B., Arbic, B. K., Bosch, W., Carrère, L., Cheng, Y., Chinn, D. S., Dushaw, B. D., Egbert, G. D., Erofeeva, S. Y., Fok, H. S., Green, J. A. M., Griffiths, S., King, M. A., Lapin, V., Lemoine, F. G., Luthcke, S. B., Lyard, F., Morison, J., Müller, M., Padman, L., Richman, J. G., Shriver, J. F., Shum, C. K., Taguchi, E., and Yi, Y.: Accuracy assessment of global barotropic ocean tide models, Rev. Geophys., 52, 243 282, doi:10.1002/2014RG000450, 2014.

Steele, M., Morley, R., and Ermold, W.: PHC: A global ocean hydrography with a high-quality Arctic Ocean, J. Clim., 14, 20792087, 2001.

Tanaka, Y., Hibiya, T., Niwa, Y., and Iwamae, N.: Numerical study of K1 internal tides in the Kuril straits, J. Geophys. Res., 115, C09016, doi:10.1029/2009JC005903, 2010.

Tanaka, Y., Yasuda, I., Hasumi, H., Tatebe, H., and Osafune, S.: Effects of the 18.6-yr modulation of tidal mixing on the North Pacific bidecadal climate variability in a coupled climate model, J. Clim., 25, 7625-7642, doi:10.1175/Jcli-D-12-00051.1, 2012.

Vlasenko, V., Stashchuk, N., Hutter, K., and Sabinin, K.: Nonlinear internal waves forced by tides near the critical latitude, Deep-Sea Res. I, 50, 317-338, 2003.

Vlasenko, V., Stashchuk, N., and Hutter, K.: Baroclinic tides. Theoretical modeling and observational evidence, Cambridge University Press, 2005.

Wang, D. P. and Mooers, C. N. K.: Coastal-trapped waves in a continuously stratified ocean, J. Phys. Oceanogr., 6, 853-863, 1976.

Wijesekera, H., Padman, L., Dillon, T., Levine, M., Paulson, C., and Pinkel, R.: The application of internal-wave dissipation models to a region of strong mixing, J. Phys. Oceanogr., 23, 269-286, 1993. 